\title{
The Mysterious Pyramid on Elephantine Island: Possible Origin of the Pyramid Code
}

\author{
Manu Seyfzadeh \\ Lake Forest, CA, USA \\ Email: Manu@cheopspyramid.com
}

How to cite this paper: Seyfzadeh, M. (2017). The Mysterious Pyramid on Elephantine Island: Possible Origin of the Pyramid Code. Archaeological Discovery, 5, 187-223.

https://doi.org/10.4236/ad.2017.54012

Received: August 26, 2017

Accepted: September 19, 2017

Published: September 22, 2017

Copyright $\odot 2017$ by author and Scientific Research Publishing Inc. This work is licensed under the Creative Commons Attribution International License (CC BY 4.0).

http://creativecommons.org/licenses/by/4.0/

(c) $\underset{\mathrm{EY}}{0}$ Open Access

\begin{abstract}
After the step pyramids of the Third Dynasty and before the true pyramids of the Fourth Dynasty, seven mysterious minor step pyramids were built by King Sneferu ${ }^{1}$ and a predecessor. None of them were tombs. Clues as to why they were built emerged from analyzing their orientation to objects in the sky worshiped by the ancient Egyptians and hinted at a renewed preoccupation with measuring time and the flow of the Nile. The first of the seven was built on the Island of Elephantine, Egypt. Its orientation suggests that an aspect of the star Sirius was being enshrined. This paper proposes that this aspect pertained to the different timings of its annual invisibility period observable from either the capital at Memphis in Lower Egypt or from Upper Egypt at Elephantine. I argue that these periods, measured in days, were converted to dimensions in cubits, and consequently these numbers and the resulting geometric relationships between them became important. The evidence presented shows that this original design principle of expressing astronomic periods as dimensions was then expanded to encode the relationship between the period of invisibility of Sirius and the sidereal orbital period of the Moon within the exterior of several of the most prominent pyramids of Egypt including the Great Pyramid. The geometry of this relationship and even the method of the expansion itself can be understood from a religious context plausibly prevailing during the peak of the Pyramid Age.
\end{abstract}

\section{Keywords}

Ancient Egypt, Old Kingdom, Pyramid Age, Elephantine, Pyramid, Meydum, Bent Pyramid, Red Pyramid, Great Pyramid, Hemiunu, Khufu, Sopdu, Sirius, Moon, Geometry, Kepler Triangle, Thoth, Ogdoad, Architecture

${ }^{1}$ Only ancient and modern Egyptian names and words will be italicized in this paper, not the Greek derivations. The English transliteration of hieroglyphic spellings is given, occasionally in phonetic type. 


\section{Introduction}

On Elephantine Island ( $\mathrm{Yebu} / \mathrm{Abu}$ ) by Aswan, Egypt lie the ruins of a peculiar Third Dynasty step pyramid Egyptologists call "cultic" (Figure 1). By size, the few cultic pyramids discovered along the Nile (Dreyer, 1980; Swelim, 2017), also known as Minor Step Pyramids (MSPs), resemble the many "cult" pyramids next to bigger main pyramids built for the deceased kings of the Old and Middle Kingdoms (Lehner, 1997); cult pyramids were usually placed in the southeast corner (e.g. G1-d; Hawass, 1996) of the funerary complex. They did not serve as a tomb for the body of the dead king, but as a symbolic tomb for the king's life-spirit ( $k a)$ according to prevailing consensus.

The tomb-less "Yebu Pyramid" like the other six MSPs, however, is not next to a larger pyramid and its ruins were only identified as a pyramid by a research team of the German Archaeological Institute in the late 1970's (Dreyer \& Kaiser, 1980). Unlike many other pyramids, but like most MSPs (Belmonte et al., 2005), it is not aligned to the four cardinal directions. Instead, it is off the cardinal cross by circa $17^{\circ}$ westward ${ }^{2}$ (Figure 2). Its faces' alignments do not imitate the direction of the flow of the Nile around the island. This somewhat contradicts the theory that MSPs were only built with the intent to serve as Nile monitors to time the floods (discussed by Belmonte et al., 2005).

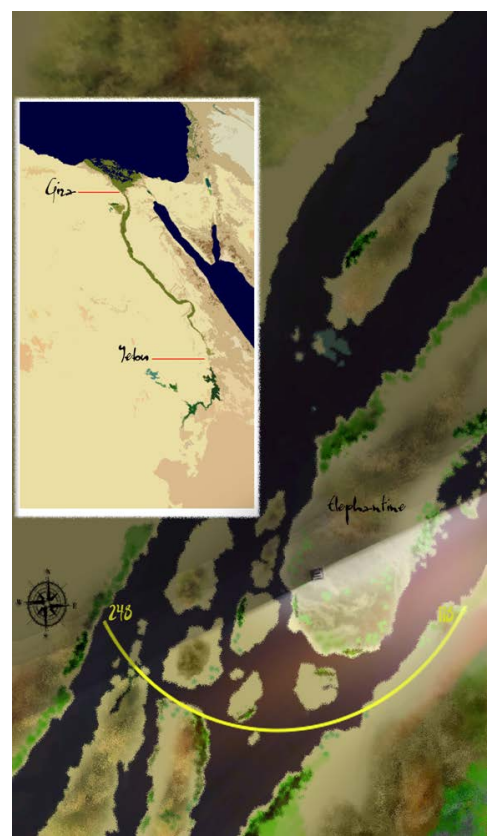

Figure 1. Location and geographic orientation of the Yebu Pyramid on Elephantine Island on the River Nile by today's Aswan, Egypt. The circa $134^{\circ}$ yellow arc shown traces the visible path of the star Sirius on its annual course in the $27^{\text {th }}$ century B.C.E. The pyramid's southeast edge points to the position of heliacal risings of Sirius at azimuth $114^{\circ}-118^{\circ}$ in this era. The inset shows the map of Egypt. Giza is on the $30^{\text {th }}$ parallel north and Yebu on the $24^{\text {th }}$. Graphic by Anthony Adomaitis, Asturmas Studios.

${ }^{2}$ The exception is the MSP at Seila just east of the Meydum Pyramid, which seems to be the first pyramid ever to be oriented to the cardinal directions (Belmonte et al., 2005). 


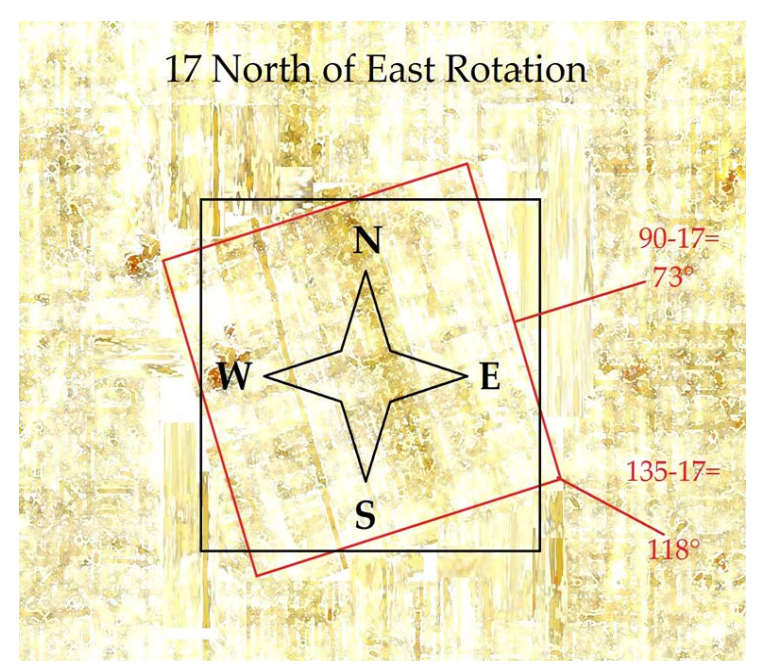

Figure 2. The Yebu Pyramid's footprint is oriented away from the cardinal directions by $\sim 17^{\circ}$ westward such that the normal over the eastern face points to an azimuth of $73^{\circ}$ and the southeast edge to $118^{\circ}$. Graphic by M.S.

Instead, the pyramid's eastern faces point to that area of the morning horizon $\left(73^{\circ}\right)$ where the Sun made its appearance on the day of a heliacal rising of the star Sirius (Belmonte et al., 2005) in the 26th century B.C., which the authors imply was the primary intent behind this exceptional orientation. However, the alternative view that MSP's were built as landmarks to measure the Nile's speed ${ }^{3}$ from Yebu to Memphis during the annual flood is not incompatible with the idea that the first, most upstream such landmark, the Yebu Pyramid, would have been time-calibrated to the reappearance of Sirius after a period of visual absence at either location, and, importantly, the difference in timing between them. This would have been a plausible motive for the variant alignment and deliberately chosen dimensions, whose theme I develop in this paper.

The Yebu Pyramid is unique in Egypt having been made entirely from granite blocks presumably from the local quarry on the island, the same material which would later be used to build the King Chamber of Khufu's pyramid, the floor of Lepsius XIII, and the casing of the valley temple below Khafre's Pyramid. It has been tentatively attributed to King Huni (Verner, 2010), last ruler of the Third Dynasty and Sneferu's presumed father. A granite cone with Hunis name was found nearby by Henri Gauthier in 1909 who thought the Yebu Pyramid's ruins were part of a Jewish temple (Swelim, 2017). However, a sealing also found in the rubble nearby identified Nebka (Seidlmayer in Hornung et al., 2006: 121) and therefore the issue of ownership of the Yebu Pyramid remains in doubt.

The mystery of its purpose likewise has endured: Why was it built, if not to serve as a tomb for either body or spirit of a dead king? Belmonte et al. suggest MSPs may have served as astronomic time markers to substitute for the progres-

${ }^{3}$ The flood's speed could vary year-over-year such that it may have arrived at Elephantine days to weeks before it inundated Memphis and the Delta (Parker, 1950; Krauss in Hornung et al., 2006: 370-372). 
sive failure of the civil calendar to synchronize with the annual flood (Belmonte et al., 2005). Thus, MSPs were meant to mark the horizontal position of the heliacal rising of Sirius ( $w p$-rnpt), the winter solstice sunset point, and the constellation Ursa Major (Mesekhtiu) according to the authors. Another intriguing possibility as to motive is the precession- and latitude-dependent temporary visual fading of the star Alkaid in Ursa Major which may have put into question its imperishable attribute ${ }^{5}$.

While Belmonte et al. do not explicitly mention this, the implication of their findings is that the Pyramid Age entered its peak phase when, and maybe because, the schematic method of keeping time and even its schematic restoration with the recognition of the Sothic cycle enshrined at Saqqara (Bauval \& Brophy, 2013) failed to satisfy the need for a more predictive measure of time to synchronize the Nile's annual flood in harmony with events in the sky.

\section{Observations, Insights, and Results}

This is the pretext from which I wish to propose here that one important aspect of exterior pyramid design during the 4th Dynasty, i.e. dimensions and angles, originated from astronomic insights gained by measuring and comparing the number of days of Sirius' invisibility at $Y e b u$ relative to Iunu $u^{6}$ and that this numerical insight became part of a building code later embedded in several well-known pyramids.

The Reconstruction: From the remains of the Yebu Pyramid, Dreyer \& Kaiser (1980) estimated that its height originally stood at $10.46 \mathrm{~m}-12.55 \mathrm{~m}$ (with or without the foundation), extended over 18.46 - 18.55 meters at the lowest base and rested on a foundation 23.7 meters long. Several models have been proposed to reconstruct its original shape based on various temple pictographs, including 3-step, 4-step, and Benben (Swelim, 2017).

Here, I want to focus on one particular reconstruction considered (Dreyer \& Kaiser, 1980; Swelim, 2017; Figure 3) verbally confirmed to me as the most probable by a member of the German archaeological field team when I first visited the site in 2017.

In Dreyer's proposal, the Yebu Pyramid had three levels above the foundation: A core reaching to the top at 24 cubits and two outer layer accretions forming two steps, 18 and 10 cubits above ground (Figure 4). Since the pyramid does not extend much above the first level in its current state, these dimensions are educated guesses on the part of the authors (Dreyer \& Kaiser, 1980; Swelim, 2017). A variance of 1 cubit up or down for the proposed dimensions above the base of each reconstruction is possible.

The Orientation: The key feature tying the Yebu Pyramid to an aspect of Sirius is in the orientation as previously pointed out by Belmonte et al. A heretofore unappreciated features of this orientation is that, due to the $-17^{\circ}$ rotation

${ }^{4}$ The visibility of the outskirts of the circumpolar region's visibility depends on precession.

${ }^{5}$ The circumpolar stars never cosmically set. To the ancient Egyptians, these stars were the immortal soul-spirits of gods who never died nor needed to resurrect.

${ }^{6}$ Heliopolis, today's Ayn Shams in north-east Cairo, Egypt. 


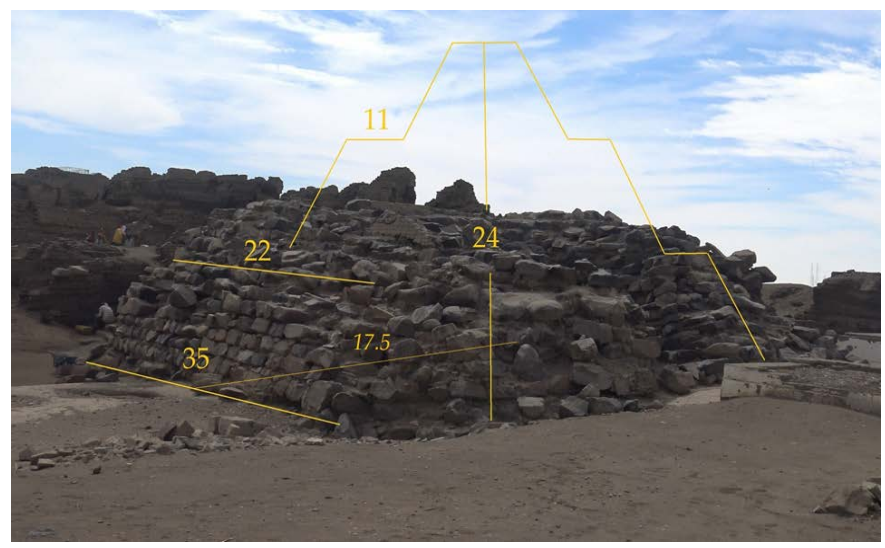

Figure 3. The current state of the Yebu Pyramid and the presumed original dimensions according to the three-step reconstruction by Dreyer and Kaiser. View from the northeast towards southwest. Photography and graphics by M.S., 2017.

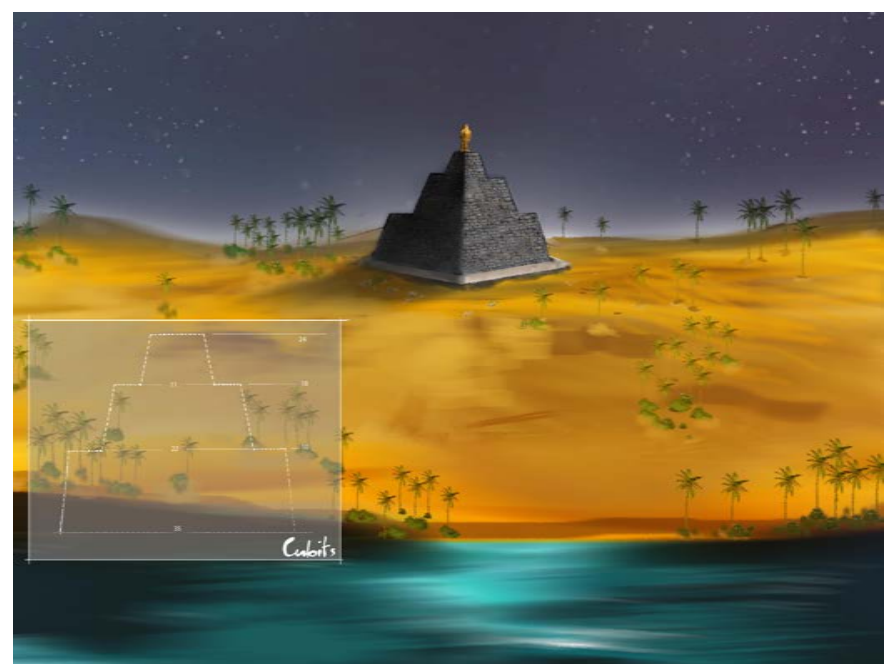

Figure 4. Recreation of the Yebu Pyramid as a three-step monument, one of several possible reconstructions. The perspective shown here is from southwest towards northeast; the southeast edge at azimuth $118^{\circ}$ is to the right. The pyramid sits on a high elevation on the island. Not drawn to scale for illustration purposes. Graphic by Anthony Adomaitis, Asturmas Studios.

relative to the cardinal directions, the southeast corner points to the horizon at an azimuth of $118^{\circ}$ (Figure 2). This is near the heading where the star Sirius heliacally rose (Sun at altitude $-8^{\circ}$; Sirius at $\left.+2^{\circ}\right)^{7}$ during 3000 B.C.E. to 2500 B.C.E. at azimuths $11512^{\circ}-113^{1} \frac{1}{2}^{\circ}$, respectively ${ }^{8}$, near Elephantine Island (using Stellarium version 0.14 .3$)^{9}$. For the time around 2600 B.C.E., the azimuth was

${ }^{7}$ This is a typical altitude bracket often cited. Schaefer has argued that a more realistic arcus visionis encompasses the altitude bracket of Sun at $-6^{\circ}$ and Sirius at $+5^{\circ}$ (Schaefer, 2000).

${ }^{8}$ Belmonte gives $115^{\circ}-107^{1 / 3}$ for 3000 B.C.-500 A.D. at Aswan. (Belmonte in Hornung et al., 2006: 384).

${ }^{9}$ The headings of Sirius Risings change with time due to precession. For the last 12,000 years the heading has gradually moved northward on the eastern half of the horizon as seen from the northern hemisphere. 
$114^{\circ}$ on heliacal risings and $118^{\circ}$ about 9 days later. Questions arise, whether heliacal risings would have been observed from the island at the relative high point where the pyramid was later built and from where most of the southeast horizon appears undulated due to hills in the distance, or from another observation point on the mainland with potentially better visibility of a flat horizon.

Reconstructing the vantage point from the position of the Yebu Pyramid is complicated by the fact that nowadays the view of the relevant part of the horizon is graced by the Archangel Michael's Coptic Orthodox Cathedral (Figure 5). However, standing on the top of the Yebu Pyramid and gazing towards the southeast with a heading of $118^{\circ}$, one would have been able to see quite far into the distance because the pyramid stood on higher ground at an elevation of $\sim 325$ feet (Google Earth) to which one adds the height of the pyramid itself ( $\sim 41$ feet) and the height of an observer ( $~ 5$ feet at eye level). Fortuitously, the hill tops behind Aswan decline for a short stretch around that heading.

It is still difficult to say with certainty, if an ancient observer standing here would have been able to spot Sirius at an above-horizon altitude of $2^{\circ}$ during its heliacal rising. Stellarium gives a range of headings, $114^{\circ}-118^{\circ}$, for the 27 th century B.C., if you vary the star's altitude between $2^{\circ}$ and $8^{\circ}$. In the 42 th century B.C., assuming visibility at $2^{\circ}$ altitude, the heading would have been $121^{\circ}$ which matches the heading of the open niche created by three boulders laying on the other side of the island to the southeast. This niche and its orientation may have originally attracted the attention of predynastic builders who erected a sacred hut there (Wells, 1985) on which the more recent renditions of Satet's temple were later constructed. This raises some interesting possibilities about when the observations leading to both temple and pyramid orientations were originally made, but is not considered in this paper's analysis. The main take-away is that there is another monument on this island which demonstrably tracked Sirius' visual appearance from its vantage point.

Wells (1985) reported astronomic measurements of the several reincarnations of the Satet temple first built into the aforementioned boulder niche in predynastic

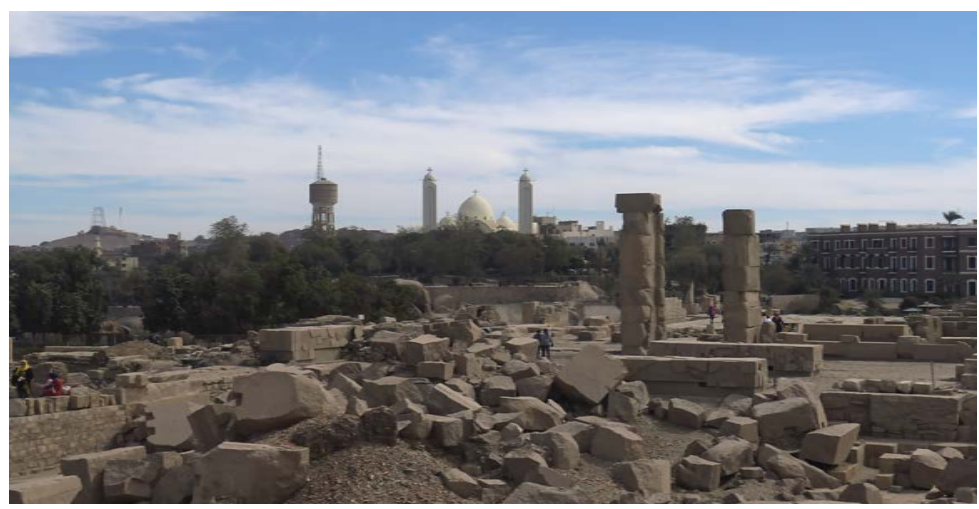

Figure 5. Approximate view from the Yebu Pyramid's southeast edge across the Nile towards southeast. The Archangel Michael's Coptic Orthodox Cathedral and a few trees are in front of that part of the horizon where Sirius heliacally arose in 27th century B.C. Photography by M.S., 2017. 
times and then rebuilt during Old, Middle, and New Kingdoms and during the Ptolemaic era (see Figure 2 in Wells' paper for a graphic showing orientations and layers). He concluded that the Satet temple, in keeping with Satet's presumed association with Sirius, was intentionally oriented towards that star. For the period ranging between Hatchepsut's New Kingdom rebuild and that of the Ptolemaic era the temple's axis was aligned to an azimuth of circa $118^{\circ}$ and $115^{\circ}$, respectively. This would indicate that the observation which led to the New Kingdom era alignment of Satet's next temple ( $\sim 15$ th century B.C.E) was taken about 16 days after a heliacal rising of Sirius (Sun at altitude $-8^{\circ}$; Sirius at $+2^{\circ}$ ), which then occurred at an azimuth of circa $111^{\circ}$ (Stellarium). From Wells' data, while the Satet temple was indeed oriented to Sirius, any alignment could not have been on the day of helical risings but several days later, when the star had already reached higher altitudes at dawn. Since it is situated at a lower elevation and slightly more south than the Yebu Pyramid, its view of the southeast horizon is more obstructed by hills nearby. In any case, it appears from Wells' Table 1 (Wells, 1985) that the temple's several rebuilds tracked the star's northward wander for over 2000 years.

Here, I will assume that during the life-time of Huni (or Nebka) Sirius became visible within an azimuth range of $114^{\circ}-118^{\circ}$ at an altitude of $2^{\circ}-8^{\circ}$ as seen from the spot where the Yebu pyramid now stands. In terms of the timing of the visual absence of Sirius, these differences could have delayed the observation by up to 7 days, if they were made from this spot on the island and not from higher ground elsewhere on the mainland. However, I suspect the latter is the case because the dimensions of the pyramid indicate the true period was known as shown below. Therefore, the Yebu pyramid may not have been the observatory, but rather a shrine on this sacred island to record observations made from an observatory elsewhere nearby ${ }^{10}$ and to mark them as pertaining to Sirius. While the Satet temple on Yebu may have been a sanctuary purely dedicated to her celestial appearance as Sirius, the pyramid, I argue, was a quantitative astronomic record built to record its timing. Rolf Krauss has argued that the best way to reconcile discrepancies in Egypt's chronology relating to schematic relative to actual variations of an Egyptian year based on $w p$-rnpt's is to anchor the reference observations to Upper Egypt, i.e. Elephantine, for most of its history (Krauss in Hornung et al., 2006: 444).

As was pointed out by Belmonte et al. (2005), the pyramid's eastern face points to that area of the horizon, at declination $161^{\circ}$ and azimuth circa $73^{\circ}$, where the Sun rose in 2570 B.C.E. on the morning when Sirius reappeared after a period of visual absence. I was not able to reproduce a helical rising of Sirius with that azimuth $\left(73^{\circ}\right)$ for a sunrise (altitude $=0^{\circ}$ ) during the 26th century B.C. at $24^{\circ} 5^{\prime} \mathrm{N} 32^{\circ} 53 \mathrm{E}$. Using Stellarium (version 0.14.3), I observed a sunrise declination of $24^{\circ}$, at azimuth circa $631^{\circ}{ }^{\circ}$, consistent with summer ${ }^{11}$, for example on

\footnotetext{
${ }^{10}$ For example, the hills southeast of St. Michael's Cathedral where the ancients quarried stone.

${ }^{11}$ Schaefer presents data that Sirius Risings occurred 92.3 - 95.8 days since a vernal equinox between 3000 B.C. and 2500 B.C., respectively (Schaefer, 2000).
} 
Julian Day ${ }^{12} 782,921$. Stellarium gives late May (e.g. J.D. 782,877) and late August (e.g. J.D. 782,973) for a sunrise declination of circa $16^{\circ}$, the earlier of which more closely coincided with the helical rising of the belt stars of Orion and was thus too early for Sirius to become visible. The latter is too late for helical risings during this era. This means the pyramid's edge seems to more accurately implicate Sirius as its orientation guide than its eastern face. The $\sim 2612^{\circ}$ north-of-due east offset of the Sun's azimuth on the day of heliacal risings during that era is a familiar angle to those who study the architecture of the Great Pyramid built a century later, specifically the angle of the passages leading into the pyramid.

The western face, whose normal points to an azimuth of $253^{\circ}$, covers the segment of the horizon of Sirius' cosmic settings in the 27th century B.C., $\sim 248^{\circ}$, though this position was certainly not observable from $Y e b u$ Island because of the high hills on the west bank of the Nile there. The difference, $248^{\circ}-114^{\circ}=$ $134^{\circ}$, is that sector of the total visual field above which Sirius theoretically could then have been seen in the night sky each year (Figure 1). The span of this arc changes with precession confounded by the proper motion of the star itself.

To sum, the orientation is consistent with the idea that the pyramid pertained to Sirius, but, in contrast to Belmonte et al. (2005), I believe the southeast edge is the more accurate indicator to that effect than the eastern face. This also supports the idea that the pyramid, more than a shrine, was designed with scientific intent. I agree with the authors that the Yebu Pyramid was not oriented with the intent to follow the course of the Nile. The fact that an edge or corner rather than a face was an orientation marker has precedence in both late predynastic and early dynastic Egypt when kings built large enclosures, so-called "fortresses of the gods" (Wilkinson, 2000: 18-19). These enclosed rectangular spaces probably symbolized the heavens, i.e. Nut. They typically had a gate at the eastern aspect of the southeast corner and at the northern aspect of the northeast corner. This architectural theme was preserved for at least 400 years prior to when the Yebu Pyramid was built (Wilkinson, 2000: 18). It is possible that these two gates opened symbolic passages to Sirius/Horus/Sopdu and Alkaid in Ursa Major (Mesekhtiu), the ox thigh of the Egyptian Zodiac representing the god Seth. This physical lay-out on the ground correlates well with the stellar theme of the Pyramid Texts and an allusion to the Ogdoad (water lilies; see discussion). According to James P. Allen's translation (Allen, 2005: 67) of inscriptions on Tetis burial chamber's west wall gable, the first spell recited to Nut reads:

[7 Recitation. Open] sky! Open Earth! Open the door to Horus, you of the enclosure wall; pull open the door to Seth, you water-lilies-and [capsize] to him as the one at the fore of his toppled wall, for Teti has passed [by you] as Atum.

The idea that these two corner-associated gates may have symbolized passages to important stars does not preclude another, i.e. that the enclosure's four corners themselves may well have symbolized the maximal excursions of the Sun at sunrise (Kheper) and sunset (Atum) during the year.

${ }^{12}$ The Julian day number is calculated in reference to January $1,4713 \mathrm{~B}$.C. which is defined as Julian day \#0. 
Having elucidated the intent behind the orientation of the pyramid, the next question is if the three-step design and its dimensions mattered too. Did the numbers in cubits have astronomic meaning or were they chosen at random? Proving intent without written evidence so professed is of course difficult. However, if one can show that quantitative observations in the sky had practical or religious (or both) significance, a circumstantial case can be made that the numbers compelled priestly planners to architecturally enshrine them in other buildings just as they thematically enshrined alignments. The burden of proof therefore demands the demonstration of a recognizable theme enshrined in more than one building. But before identifying a putative architectural theme emerging from the Yebu Pyramid, I must first build a contextual bridge between astronomy and myth for those readers not familiar with how these two may relate and then I will demonstrate that what was numerically observed in the sky found its way into the architecture of the buildings on the ground, specifically their dimensions. The focus of the following section is to confirm that during the initial phase of the Old Kingdom, Horus was believed to be Sopdu in the sky, that his annual invisibility period of 70 days was recognized as a two-stage journey from west to east through the underworld each 35 days-long, and that remnants of this belief were preserved in the Pyramid Texts, even after the Egyptian state converted (back) to a predominantly solar worship.

Astronomy and Religion: The day of the heliacal rising of the star system Sirius A and B (Egyptian: spd, "Sopdu", i.e. sharp tooth, or sharp one; Greek: Sothis) in the constellation Canis Major ("Sopdet"), was the oldest known Egyptian New Year's Day, called wp-rnpt ("wep-renpit"; "Opening of the Year"). In the Edfu texts (Fairman, 1935), this day commemorated the beginning of the battles of Horus of Behdet with Horus' uncle/brother Set to revenge Set's slaying of Horus' father Osiris. Sopdu in the sky and Horus in myth therefore appeared on the same day. Horus of Behdet is described as a winged disk as early as the Fifth Dynasty (Shonkwiler, 2014: 63-66) and his attribute is that of a harpooner attested in as early as the Middle Kingdom (Shonkwiler, 2014: 234).

Besides their synchronous appearance, the harpoon/spear of Horus semantically relates to the meaning of $s p d$, i.e. a sharp projectile reminiscent of a falcon and the "sharp" horizontal rays of bright light of Sopdu as it "cuts" through the predawn morning haze. Horus was also associated with the Sun as Horakhty ("Horus of Two Horizons") in the Pyramid Texts and in the New Kingdom Horakhty appears to be the name of the celestial counterpart of the Great Sphinx monument at Giza (Schoch \& Bauval, 2017).

$W p$-rnpt came after a period of visual absence of Sopdu from the dusk-to-dawn starry sky. This period began each year when the star cosmically set on the southwestern horizon and could no longer be seen either late before sunrise, early after sunset, or anytime during the night. Sopdu's invisibility ended when it reappeared on its heliacal rising and this became wp-rnpt because it portended the yearly inundation of the Nile during Egypt's summer. Initially observing a natural lunar year with schematic intercalations synchronized to wp-rnpts, early dynastic Egyptians inaugurated a new, purely schematic, calendar circa 3000-2800 
B.C.E. whose first day happened to coincide with $w p$-rnpt in the 28th century B.C.E. ${ }^{13}$ (Parker, 1950). Since this new calendar was not synchronized to the natural period between wp-rnpts, the two cycles, natural and man-made years, gradually dissociated. The schematic Sothic Super-Cycle created by this drift was presumably recognized and numerically enshrined by Imhotep (Bauval \& Brophy, 2013). Instead of $w p$-rnpt's, Nile floods were timed by direct measurements at, for example, Elephantine Island. The Egyptians' mythological interpretation of wp-rnpt was the resurrection of the soul-spirit of Horus and the Horus-Kings.

Factors which determine the timing and horizontal position of cosmic settings and heliacal risings of stars and planets have been reviewed by Belmonte (in Hornung et al., 2006: 380-385) and Schaefer (Schaefer, 2000). These factors conspire to produce an annular period of visual absence of Sirius of about 68-71 days at a latitude of $30^{\circ}$ north, the parallel which runs through the area of Cairo, ancient Memphis, Giza, and Iunu (Gautschy, 2012). A rough rule of thumb is that each degree latitude counts for one-day difference with respect to both cosmic settings and heliacal risings. In other words, the further south an observer is positioned on the northern hemisphere, the shorter the invisibility period (Figure 6 and Figure 7). As a result, Sirius sets one day later and heliacally rises one day earlier summing up to about 2 days per each one-degree latitude as the star's visible arcuate path across the Meridian steepens and lengthens. The exact dates for various locations and time frames in Egypt can be astronomically computed and have been published (Gautschy, 2012). These dates are theoretical assuming ideal visibility. Variation would have occurred due to cloud cover and air moisture which have been reconstructed for ancient dates (Schaefer, 2000) ${ }^{14}$. What ancient Egyptian astronomer-priests saw and what was possible were therefore close, but likely not always exact matches with computed dates unless averaged over years.

Sirius' cosmic settings have no clearly identifiable metaphorical counterpart to wp-rnpt in the extant corpus of discovered scripture, except maybe the gouging by Set of Horus' left eye, but there are hints in the Pyramid Texts where one would expect them: On the west wall of the sarcophagus chamber. "The toothless calf" of Recitation 1 in Unas' tomb could be the "head-first" cosmically setting Canis Major without its "tooth", i.e. Sopdu, already "swallowed up by Earth" below the southwest horizon. In Recitation 2, "the head of the great black bull has been severed" could plausibly mean the likewise cosmically setting Taurus constellation in Canis Major's vicinity (Allen, 2005: 17; Allen's take differs based on endnote 6).

New Kingdom records show that the death of a Horus king initiated a 70-day period (Smith, 2009, e.g. Theban Tomb 110 Stele of Dhouty, 18th Dynasty) during which he was mummified into the imagined representation of an Osiris king and prepared for resurrection thus reenacting the Osiris-Isis-Horus procreation myth. Sopdu was the visible spirit of the dead Horus king in the west resurrected

\footnotetext{
${ }^{13}$ Deduced by winding the clock back by two Sothic cycles from a historically confirmed heliacal rising of Sirius on July 21, 140 C.E. recorded by the Roman Censorinus, astronomically corrected to July 20, 139 C.E. A Sothic cycle is 1460 Julian years or 1461 Egyptian civil year. Schaefer formally computed the Sothic cycle to be 1457 years \pm 20 (Schaefer, 2000).

${ }^{14}$ Schaefer has calculated an extinction coefficient of 0.35 for Egypt (Schaefer, 2000).
} 


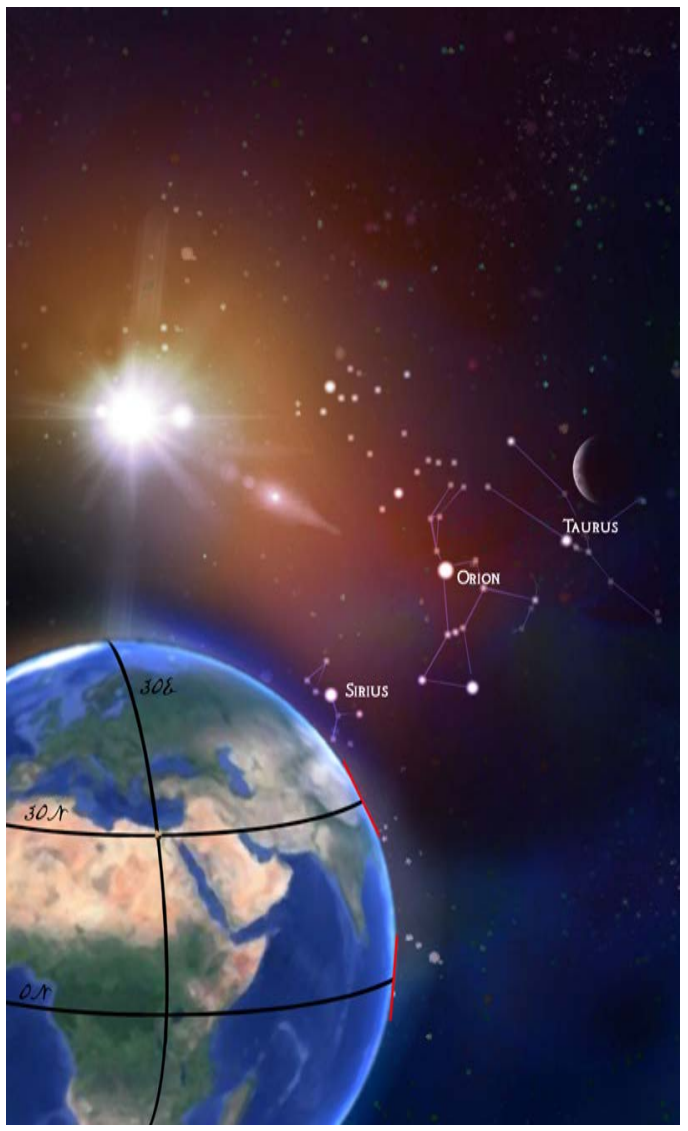

Figure 6. Variance of an observer's horizon's angle with latitude on the northern hemisphere shown here between Giza and the equator for maximal visual illustration. The steeper the angle, the more readily does the curved horizon block the sun for Sirius to stay visible at dawn. A heliacal rising can be seen at the equator in this view, but not at Giza. Note that Earth rotates towards the sun from west to east, i.e. left to right from this perspective. Earth's nocturnal half shown illuminated for illustration only. Graphic by Anthony Adomaitis, Asturmas Studios.

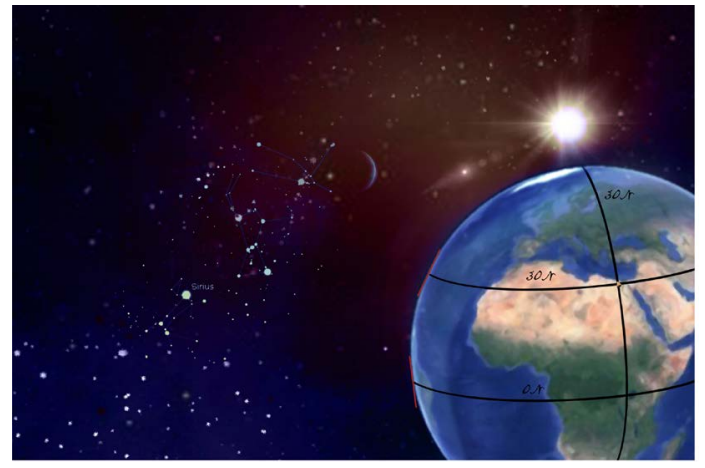

Figure 7. The alignment at dusk before a cosmic setting as seen from Giza or at the equator. The steeper horizon at the equator blocks the sun to the west after sunset and the star can still be seen in the southwest. At higher latitudes, e.g. Giza, the star disappears below the horizon before the sun sets. This initiates the invisibility period which ends when the star rises heliacally (Figure 6). Note that Earth rotates away from the sun in this perspective, i.e. from west to east towards the right. Earth's nocturnal half shown illuminated for illustration only. Graphic by Anthony Adomaitis, Asturmas Studios. 
in the east 70 days later. The unseen passage after death through the underworld (duat) was imagined in mythical form as a union with Osiris which ended in the rebirth of the king's reunified, non-corporeal soul and spirit visually confirmed by the sudden appearance of Sopdu from within Sopdet (Canis Major, Isis). The identity of Horus with Sopdu can be established about eight centuries prior in King Unas' Pyramid Text Spell/Utterance \#262 (Allen, 2005: 47; Recitation 172):

172 Recitation. Do not be ignorant of Unis, Sharp Horus, since you know him and he knows you. Do not be ignorant of Unis, Sharp Horus, who calls you Difficult.

Allen's translation "Sharp Horus" comes from the original hieroglyphic transliteration " $h r w$ spd". Clues as to Horus/Sopdu's fate can be read in the Pyramid Texts of King Pepi I (Pepi I, Recitations 479 - 480 \& 520, Allen, 2005: 164-165 \&184; relevant segment shown, square brackets indicate omitted segments not relevant. End-note markers omitted from text), which according to James P. Allen tell us:

479 Recitation. You two kites atop Thoth's wing, you two on the crown of Wanderer's head, fetch that (ferryboat) for this Pepi, put him on yonder side. This Pepi is on an urgent mission of Horus.

480 Recitation. [...]

Isis has come, Nephthys has come-one of them from the west, one of them from the east, one of them as a screecher, one of them [as] a kite-and they have found Osiris after his brother Seth threw him down in Nedit, when Osiris Pepi said: "You should go away from me," and his identity of Sokar came into being [...]

520 Recitation. Osiris Pepi, you should not go away in those eastern lands, but you should go away into those western lands, in the path of the Sun's followers. [...]

Since you are the one who prevents them from turning around from within your arms, you should go forth toward them, ba as one fully born, sharp as one fully born, in your identity of Sopdu, your flail in your (one) arm, your scepter behind your (other) arm, and those of the nighttime shall fall on their face to you, and the Imperishable Stars shall kneel to you.

Therefore, the cosmic setting of Sirius in the west was likely seen as the symbol of the dying Horus King departing the realm of the living and entering the realm of the dead to where it was to be escorted by Nephthys from the west and then back to the living with Isis from the east. However, if this interpretation is correct and the astronomical cycle implied by it is that of the star Sirius, a possible conflict arises with the general theme of the Pyramid Texts according to prevailing interpretation.

It must be kept in mind that the earliest known version of the Pyramid texts dates to the late Pyramid Age, 200 - 250 years after the events on which this paper focuses. Only fragments of written evidence exist with few clues as to the re- 
ligious beliefs of the people alive during the early and peak Pyramid Age (2670-2450 B.C.E.). Besides inscriptions on tomb wall and steles, the bulk of the evidence lies in the architecture of Third and Fourth Dynastic monuments themselves (Schoch \& Bauval, 2017) especially in alignments and orientations relative to the day and night sky as it varied with astronomic epochs due to precession. This preoccupation with alignments of megalithic structures had its roots in much more ancient practices (Bauval \& Brophy, 2013). Both solar (stone circle gates) and stellar (megalithic lines) themes can be identified at Nabta Playa and the common thread seems to be an awareness of several celestial cycles of time, both short, long, and very long, apparently motivated by the cycles of rain. Before dynastic Egyptians wrote symbols with mallets, chisels, reeds and inkwells, their predynastic ancestors recorded what they saw in the sky by building stone monuments and this architectural culture did not stop when civilization began.

The astronomic cycle most likely described by the Pyramid Texts of the late Fifth and Sixth Dynasty is the daily solar cycle according to experts (Allen, 2005). To the ancient Egyptians, the Sun died each evening in the west, resurrected in the fifth hour of the night within the mythical tomb (or the body) of Osiris' and was reborn at dawn in the east through the birth canal of Osiris' mother, the sky goddess Nut. The dead king's soul was to retrace this journey and follow the Sun to become an immortalized spirit. The lay-out of the pyramid chambers and corridors into which the texts were inscribed mirror this theme, but there is one important caveat the experts admit: The texts point to an exit for the king's spirit through the ascending passage towards north, not through the tripartite serdab, symbolizing Nut's birth canal, towards east (Allen, 2005).

A north exit means even the ancient Egyptians of the late Pyramid Age believed that the king's soul ultimately went to the northern stars and not to the rising Sun no matter "our" interpretations of the Pyramid Texts. The most striking example of this ultimate destiny desired are the four passages emanating from the King and Queen Chambers of the Great Pyramid (Bauval \& Gilbert, 1994). Unlike the Sun, Moon, and most stars, the circumpolar stars, with one important possible exception (see below), never "died" on or resurrected from below the horizon at dawn. They never disappeared from the night sky throughout the year. If they suddenly had disappeared, as a result of precession for example, religious turbulence could have materialized.

A north exit also means that the Pyramid Texts probably do not only refer to the daily solar cycle, but also to longer movements including those of the stars, the Moon and maybe even planets. We cannot rule this out a priori even based on the most recent translations. Bauval (in Schoch \& Bauval, 2017: 222-223) for example has argued that King Unas' Pyramid Text Spell/Utterance \#263 (Recitation 173, Allen, 2005) can be interpreted to describe the Sun's gradual advance from the west side of the Milky Way (mirroring the west bank of the Nile) to the eastern horizon over a period of several days after which it rose in the constella- 
tion Leo on $w p-r n p t^{15}$. In other words, the mythical journey described in this spell is not the daily movement of the Sun across the sunlit sky, but an eastward migration across the map of stars, whose immediate westward "rear view" is observable each day in the predawn hour just before sunrise. Demonstrably, that journey is 70 days long (Schoch \& Bauval, 2017: 221-224).

In my opinion, Bauval is justified in his interpretation of Recitation 173, because its astronomic context is established at the end of Recitation 172, where a compelling allusion to the Milky Way is made (Recitation 172, Allen, 2005: 48. square brackets indicate omitted segments not relevant). According to James P. Allen's translation:

172 Recitation [...]

There is no one who requires his fare for the great ferry; there is no one who bars him from the White Palace of the great ones at the Beaten Path of Stars-for look, Unis has reached the sky's height.

Unis has seen his cobra in the Nightboat: Unis is the one who rows in it. He has recognized the uraeus in the Dayboat: Unis is the one who bails it. The populace have witnessed him. The sky's hail-clouds have taken him that they might elevate Unis to the Sun.

The concurrence to which Bauval refers unfolded around 2300 B.C.E. when the Pyramid Texts were being inscribed into the pyramids of the Fifth and Sixth Dynasty. Recitation 172 even hints that this was an observable phenomenon (“The populace have witnessed him"). Therefore, this journey across the Milky Way cannot possibly describe an imagined path through the duat lasting only one night. This puts into doubt the notion that the Pyramid Texts should be viewed in one dimension along an only solar theme, even if this theme seems to have dominated beliefs in the late phase of the Old Kingdom.

Further evidence of observable movements across a stellar map can be found in Teti I's Recitation 19 (Allen, 2005: 69), where reference is made to the crossing of "Kenmut". Kenmut was the name of a decan, a group of stars which includes the constellation Leo. The crossing of a decan took the Sun, on average, 10 days $^{16}$. I think the best explanation, namely the one provided by Robert Bauval, is that some of the cycles described in the Pyramid Texts describe the apparent movements of the Sun relative to the map of the stars. These cycles last longer than one day. But even apparent trans-horizontal movements of certain stars, e.g. Sopdu and Sah (Orion), across sky and underworld were recognized.

A movement of Sah across the sky, unrelated to the sun, to which the Pyramid Texts refer (Recitation 147; Allen, 2015: 31) was commemorated during the Old Kingdom by the Sokar Festival on IV Shemu 26 (116 days after wp-rnpt). This festival vividly demonstrates how the Egyptians mythically marked celestial

\footnotetext{
${ }^{15}$ To clarify, the visible part of the Milky Way just before dawn, gradually shifts eastward revealing progressively more of itself to an observer eventually followed by the stars of the ecliptic to the east of the Milky Way, e.g. those is Gemini and Cancer, until Regulus in Leo is reached after 70 days. Around 2300 B.C.E, this day was also the once-in-a-year day of helical risings of Sirius.

${ }^{16}$ And one year to cross all 36 decans. Note the mention of a decan proves they were known then.
} 
transitions and half-way points: At dawn on this day, the Orion (sah) constellation sets in the west and "suddenly" appears again in the east at dusk on the next day. These are not cosmic settings or helical risings. The sight of this bewildering west-east "cosmic leap" inspired a ritualistic procession of Sokar's Henu barque "around" an unknown building and this ancient ritual goes back to early dynastic times proving its importance (Gaballa \& Kitchen, 1969).

A spiritual north exit implied by the Pyramid Texts also comports well with the documented alignments of man-made structures over thousands of years at Nabta Playa and Saqqara (Bauval \& Brophy, 2013), and some of the cultic pyramids (Belmonte et al., 2005) towards the circumpolar regions particularly the constellation Ursa Major. Another example is the statue of Djoser inside a ser$d a b$ on the north side of the Step Pyramid which seems to stare through a small hole oriented to the star Alkaid in Ursa Major (Bauval \& Brophy, 2013).

The overarching theme of the pyramid texts may well be solar, but the stellar theme still reverberates hinting that the solar theme was either added de novo or revived from primordial worship, but did not replace it. In fact, a discontinuous, added emphasis on $R e$ is supported by evidence of a sudden religious shift at the time of Khufu and his heirs during a time which preceded the first known Pyramid Texts (Unas) by about two centuries.

Religious Shift: This shift during the Fourth Dynasty at the peak of the Pyramid Age has been proposed by Mark Lehner and Zahi Hawass based on archaeological evidence (Hawass, 1996: 391-394) and by American Egyptologist James Henry Breasted (Breasted, 1912: 101-102) based on his reading of the Pyramid Texts. The archaeological evidence ${ }^{17}$, several unfinished subterranean passages and corridors, is interpreted to mean that Khufu's (a.k.a Khnum-Khuf) planners abandoned construction of a fourth subsidiary pyramid in the east field north of the future causeway and one possible pyramid and a tomb, G1-X and G-7000x on the other side to the south in his 5th regnal year. Instead, according to Hawass, Khufu's mortuary temple which faced east towards the sunrise was widened and the causeway was built over the "trial passages", also towards east ${ }^{18}$. This change in plans, according to Hawass, correlated with Khufu's embrace of "Re", presumably attenuating his worship of Khnum. Khufu's heirs, beginning with Djedefre, added the suffix " $R e$ " to their throne names, the "Sa-Re" nomen. A total solar eclipse over Memphis (Seyfzadeh, pending publication; a draft can be accessed at the author's Academia.edu profile), may have precipitated this shift.

Bauval, countering Breasted, has argued that the solar theme in the Pyramid Texts is more ancient than the stellar theme evidenced by an astronomically prehistoric alignment of an older Sphinx and causeway, later used by Khafre, ${ }^{17}$ Originally, Vyse and Perring who discovered the "trial passages" proposed that they were meant for an additional queen pyramid. Petrie noted their similarity to those in the Great Pyramid. Lehner disputed that they were only trials based on ancient repair work he observed.

${ }^{18}$ Selim Hassan (Hassan, 1960: 20) had a different interpretation. He speculated that the first of the two initiated passages was an underpass below Khufu's causeway and could not explain the second one. 
towards Regulus in Leo due east on wp-rnpt and to the Sunrise on 1 Tybi (121 days after the vernal equinox) when Leo more fully appears, respectively, in the 11th millennium B.C.E. The two views need not be incompatible. A prehistoric solar theme may have been superseded by a predynastic stellar theme imported by migrants from the Nabta culture settling in the Nile Valley when the Sahara became inhabitable (Bauval \& Brophy, 2013). This stellar theme may have dominated Egyptian Religion until the Fourth Dynasty when shifting religious sentiment once again looked to $R e$.

No major religious shift occurs without resistance, especially from conservative elements among the guardians of the faith, the priesthood. Therefore, it is possible that if such elements were influential and had input into pyramid design that themes of the previously prevailing star cult and themes of the presumably even older cosmogony of the Ogdoad, a theology formulated in the city of Thoth Hermopolis magna ("Khemenu"), became embedded along with the new Sun cult theme dedicated to Re. This may explain why the star cult maintained its mythical influence on the Pyramid Texts.

Descent and Ascent: After his heavenly fall to death in the west, Horus was believed to have embarked on a journey through the underworld and was resurrected midway through the life-giving power of Osiris (who then reveals as Sokar) and his mother Isis. Thus reborn, he would complete his journey and resurface on wp-rnpt 70 days later.

This journey could be divided into two half-periods, descent and ascent, each 35-days long and these two periods seemed to have been enshrined in the mummification process attested by the first tale of Setna Khamwese and other late period and Greco-Roman references (Burton, 1972: 265-266): 35 days of preparing the body (dissection, drying, embalming), and 35 days to wrap it in linens with ceremonies on day 4 and 16; coffining and entombing on day 70 . Variations of the overall length can partly be explained with the actual variations of observable invisibility periods of Sirius, but 70 days appeared to be important.

It could be argued that until the mummification technique sufficiently advanced in the New Kingdom, the Egyptians did not attribute importance to two 35-day sub-periods, even if the total (70 days) had long been recognized as a sacred period. Nevertheless, the elements and ingredients of mummification, i.e. the washing after disemboweling ${ }^{19}$ to lighten the load on the heart ("outflow" of that which makes the heart weary), incensing, desiccation and disinfection, anointing ${ }^{20}$, make-up, and linen wrap are all ritualistically recapitulated as part of the Offering Ritual in the early set of spells of the Pyramid Texts (e.g. Recitations 19-24; 46-54; Allen, 2005: 19-20, 22).

Further evidence needed would be an, yet elusive, record of an Old Kingdom context-related festival or feast, similar to the Feast of Khnum-Re, dated to IV Shemu 1, i.e. 34/35 days before Thoth 1 . The entry for this temple calendar date

${ }^{19}$ This practice during the Old Kingdom can be inferred from the discovery of Canopic Jars, for example in the tomb of Hetepheres I, Khufu's mother.

${ }^{20}$ The use of Natron from Upper and Lower Egypt and Pine oil are mentioned. 
recorded on the temple of Khnum at Esna according to Sherif El-Sabban (El-Sabban, 2000: 168) reads:

Feast of Khnum-Re, chief of Esna; Re says to this god: "May Nut not give birth this month, because I was myself born in it!"

Even though this temple dates to the Greco-Roman period, the meaning of this entry has timeless astronomic roots. At the half-way point between a cosmic setting of Sirius and its helical rising, one observes the entire constellation Taurus above the predawn sky concurrent with Orion's helical rising. There is evidence to suggest that Khnum, at times in Egypt's history, was associated with this constellation (Seyfzadeh, pending publication) ${ }^{21}$. In other words, Re "speaks" these words to Khnum-Re, possibly seen as the constellation we now call Taurus. Re's own birth, 35 days ahead of Horus/Sopdu, on this date reveals his union with Osiris/Sah. This is the same duality found in the much older Pyramid Texts (Allen, 2005: 7). It appears that astronomic concurrences inspired these dual identities described in religious myth.

Another example of specially recognized half-way points in a celestial cycle are the 12 groups of 4 deities in "the list of 59 deities" marking the four main Moon phases of the twelve-month lunar year (Parker, 1950).

Horus Duality: The journey from one part of the horizon, through the duat, to the other may have led to Horus' other name in the Pyramid Texts: Hor-akhty, Horus of the two horizons, later Re-Horakhty once explicitly associated with the Sun, which likewise passes two horizons. The names Horemakhet and Horakhty were also attributed to the Great Sphinx as recorded on the Dream Stele. Bauval argues the two names suggest distinct identities for two statues shown on the stele, not one entity shown twice for symmetry (Schoch \& Bauval, 2017: 174-180). Horakhty in the east was the celestial starry image of the physical Sphinx, Horemakhet in the west. That image was the constellation Leo (Schoch \& Bauval, 2017: 152-153).

This insight provides an important clue as to how the resurrection cycle described by the Pyramid Texts should be interpreted. The association by name between lion and falcon gods, both worshiped and feared as Earth-bound emissaries of Re, hint at dual origins, a solar and a stellar cult, of the god Horakhty who may have been a stellar entity associated with Sopdu from predynastic times through the first half of the Old Kingdom. Later, when $R e$ (re)-emerged as the chief deity, the Horus cult became merged with the Sun cult reflected in the Pyramid Texts by the dual nature of Horus as $S o p d u$, i.e. $h r w s p d$, and Horus as $R e$, i.e. Horakhty. This merging can be explained astronomically as concurrences which, in turn, may explain the dual, and confusing iconography and names.

The politically wise move in projecting a new religious theme is not to abolish

\footnotetext{
${ }^{21}$ For example, the extinct ram species Ovis longipes and hymns devoted to Amun at the Temple of the Plow at the Kharga Oasis (Seyfzadeh, pending publication; a draft can be accessed at the author's Academia.edu profile).
} 
the old one, but to incorporate it, e.g. the dual display of both Horus and Seth on Khasekhemwy's serekh banner after winning a civil war against Lower Egypt at the end of the Second Dynasty. It seems that such a "velvet" transformation may have occurred during the Old Kingdom and the Pyramid Texts emulated it later.

Latitude and Length: In astronomic terms, Horus' journey spans over an arc distance at the horizon (see Figure 1) which very slowly changes with preces$\operatorname{sion}^{22}$ and proper motion of Sirius. The observer's latitude mostly determines the steepness of Sirius' arcuate path across this zone of the night sky and it is the steepness of the arc delineating it which determines the duration of visibility and, thereby, the duration of invisibility from sight each year, the two durations being inversely related; the lower the latitude, the steeper the path, the longer the annual period of visibility, and the shorter the period of invisibility each year (Figure 6).

This then reveals a crucial geometric insight one may learn, or incidentally import, from observing a certain arc distance of Earth's orbit at different latitudes: The measure of one curvature using another. This measure is the trade-off in days between the observer's latitudes tracking a certain segment of Earth's orbit marked by a star's invisibility, and that same segment observed in days of invisibility at any fixed latitude. For example, if one traveled from Giza at $30^{\circ}$ North to a place $47^{\circ}$ further South, i.e. $-17^{\circ}$ (below the equator), there would be no (or almost no) invisibility period of Sirius. It would (almost) always be visible throughout the year. Therefore, a $47^{\circ}$ change in latitude is roughly equivalent to staying at $30^{\circ}$ and waiting 70 days.

The change in days of Sirius' invisibility period with latitude thus becomes a measure of the curvature of Earth's orbit around the Sun in terms of the curvature and thus circumference of Planet Earth itself (Figure 6 and Figure 7) and explains how astronomic observations can lead to the incidental and unintentional import of other, related properties of Earth's dimensions, and the discovery of geometric relationships long before their official recognition. Ancient Egyptian astronomer-priests had a keen interest observing the Sun, planets, the Moon, and the stars. What would they have seen had they counted the days of absence of Sopdu?

Cycles, Numbers, and Geometry: Had they measured this period at Iunu, they would have counted 69 - 70 days during the century which passed during the Third Dynasty ( 2670-2600 B.C.). The true period begins on the evening of the star's last appearance and ends on the morning when it first reappears. The elapsed time of this interval is between 69 and 70 days. Had they measured this period from an observatory at Elephantine Island ( $24^{\circ}$ north), they would have measured 58 - 59 days. This 11-day difference can be explained with celestial mechanics and Earth's geometry (Ingham, 1969), but to the ancient Egyptians this number may have related to the speed of the Nile's flood in relation to the

\footnotetext{
${ }^{22}$ In 2600 B.C.E. at the latitude of Memphis, for example the arc distance's span of the extent of Sirius' visible annual movement was from azimuth $114^{\circ}-246^{\circ}$, i.e. $132^{\circ}$ compared to $134^{\circ}$ at $Y e b u$. By contrast, in 10,500 B.C.E., the span was less than $165^{\circ}-195^{\circ}$, i.e. only $30^{\circ}$.
} 
speed of Horus' resurrection. Hence, it would have been regarded important. The number 11, for example, features prominently in the interior design of the Great Pyramid (Gantenbrink, 1999; Robert Bauval, personal communication) as the basic grid unit.

Geometrically 11/69-70, closely approximates how the radius $\mathrm{r}$ of a circle relates to its circumference $C$ and 22/69-70 is as any diameter $D$ is to $C$ (Figure 8), i.e. a geometric relationship which relates a straight line to a curve. The geometry of circles and curves was on the mind of Third Dynasty Egyptians. An architect left evidence (Limestone flake, ostracon, Saqqara, disc. 1925, Cairo Museum) in the form of an ostracon on which s/he quantified the curvature of a circle in terms of vertical projections to a base (Figure 9). The ratio, 22/69 or

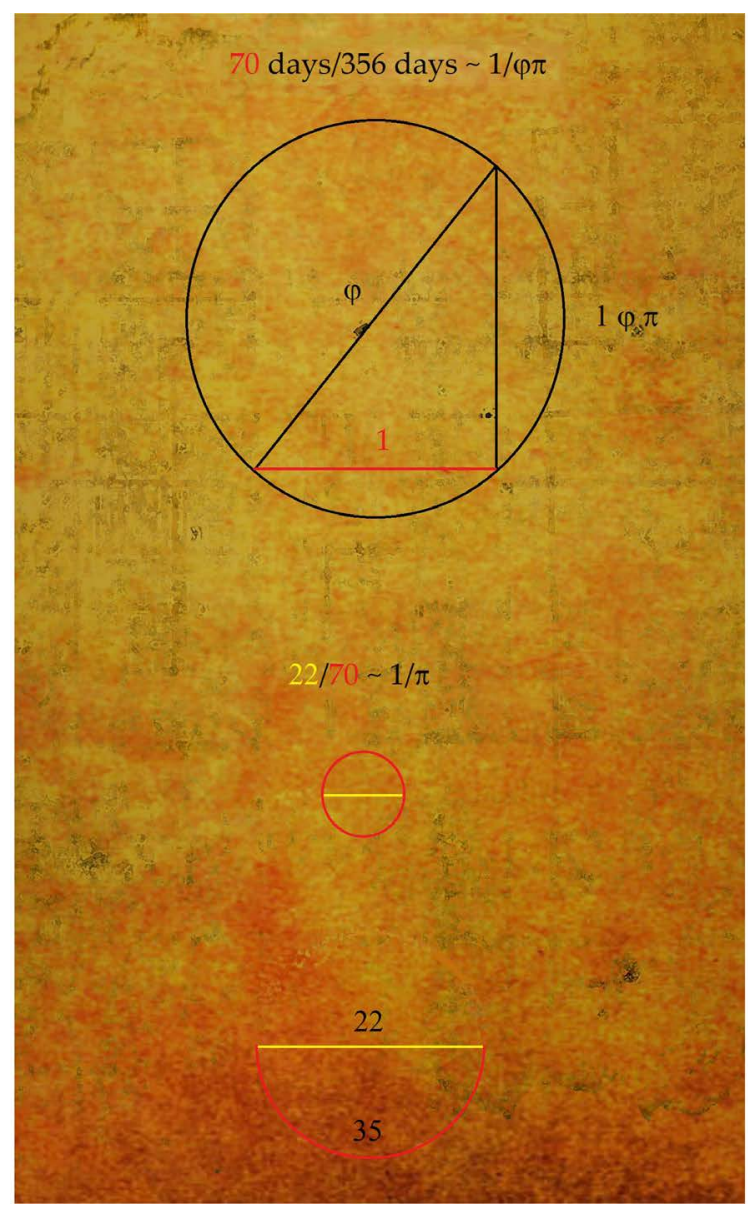

Figure 8. Two classic interrelated geometric relationships can be approximated from an observable measure of Earth's curvature and a sidereal lunar year: The number of days of invisibility of Sirius at Iunu and $\mathrm{Yebu}, 59$ days and 70 days, respectively, with the difference of 11 , and 356 days. 70 days can be expressed as the short leg of a Kepler Triangle $(1: \sqrt{ } \varphi: \varphi)$ with a corresponding circle of 356 whose diameter is 113, and 22 days can be expressed as the diameter (radius 11) of a circle 70 days long or of a half-circle 35 days long. Graphic by M.S. 


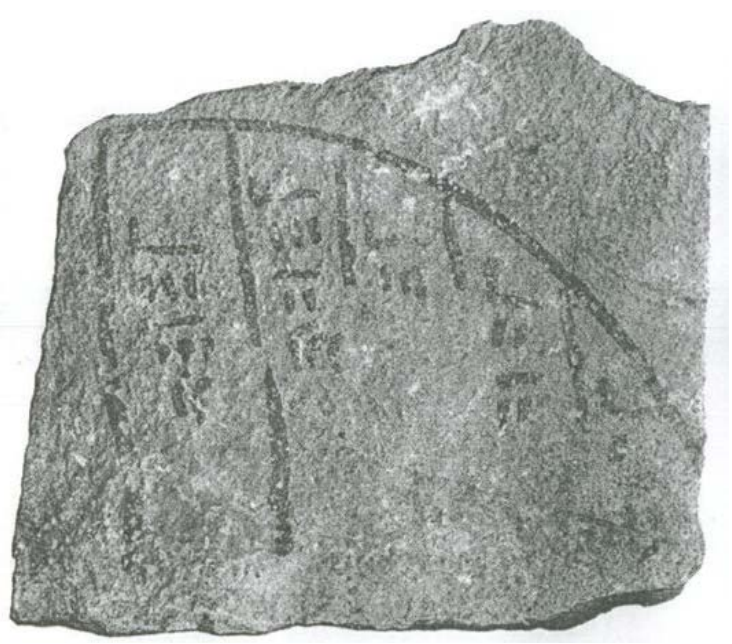

Figure 9. The Saqqara Ostracon dated to the Third Dynasty. It shows the varying heights in cubits of an ellipsoid arch and demonstrates that Third Dynasty architects were preoccupied with how to define curvature linearly by vertical projection onto a linear base. Public Domain. Direct link to image: https://upload.wikimedia.org/wikipedia/commons/d/dc/ Saqqara_ostracon.jpg

$22 / 70$, is a rare instance when this relationship can be closely expressed in whole numbers (integers) and would have been a geometric curiosity obtained from astronomical observations.

The heavenly source of this geometric insight would have attached to it the sacred attribute of Horus' resurrection cycle expressed numerically as integers and graphically as a circle. I want to emphasize, therefore, that there is no need to propose that the ancient Egyptians had a concept of the numerical value of $\pi$ ( $3^{1 / 7}$ cubits, e.g.) except in terms of the complex geometric fractions I just described which arguably are more meaningful than what results from their computation. The New Kingdom-dated Rhind Papyrus describes how Egyptian mathematicians simplified complex fractions as sums of unit fractions, e.g. $3 / 4$ became $1 / 2+1 / 4$, but the purpose of such mathematical operations would have differed from the complex fraction described here which can instead be geometrically expressed with circles, diameters, and triangles.

\section{Discussion}

What was the idea behind the design of the Pyramid on Elephantine Island? It was built at a time when both schematic and natural measures of time may have revealed their flaws. Wp-rnpt had wandered on the horizon and drifted away from I Shemu 1, later called Thoth 1 . The imperishable nature of the circumpolar stars may have been in doubt. If the order of time could be disturbed so could the order of annular floods from Khnum's caverns under Yebu. This threat is a plausible context within which MSPs may be understood as a key transition 
during the Pyramid Age from marking star positions to timing them. If there was a Pyramid Code, it may have been born on this island as a new measure of time to be eventually enshrined in the lengths of true pyramid walls.

At $Y e b u$, I propose the architect wanted to numerically record the timing of Horus' journey through the duat. Step dimensions measured in cubits represented days of Sopdu's invisibility at Iunu, Yebu, and the difference between them. The southeast edge was to mark wp-rnpt. This orientation "time-stamped" the pyramid relative to $w p$-rnpt's horizon drift with precession. Six similar pyramids of this cultic variety were erected along the Nile up to the Faiyum marking various celestial targets. The last, $10 \mathrm{~km}$ west of Meydum and headed due north (Belmonte et al., 2005), has a longer base at 50 cubits but in Swelim's reconstruction layer 1's base is 35 cubits and the base of the core is 22 cubits, both preserved dimensions in the other six MSPs (Swelim, 2017).

If we convert meters into royal Egyptian cubits, Dreyer \& Kaiser's three-step model of the Yebu Pyramid yields a height of 24 cubits with 35 cubits, 22, and 11 on the three steps' bases (Figure 3 and Figure 10). 35 cubits represented both the time of Sopdu's imagined descent into the duat guarded by Nephthys and his ascent escorted by Isis culminating in wp-rnpt; a 70-day journey through the underworld at Memphis whose half-way point was the life-renewing union with Osiris. This period was represented by the west and south faces of the pyramid at ground base. The ground level represented the view from Iunu/Memphis in this model, i.e. the reference period.

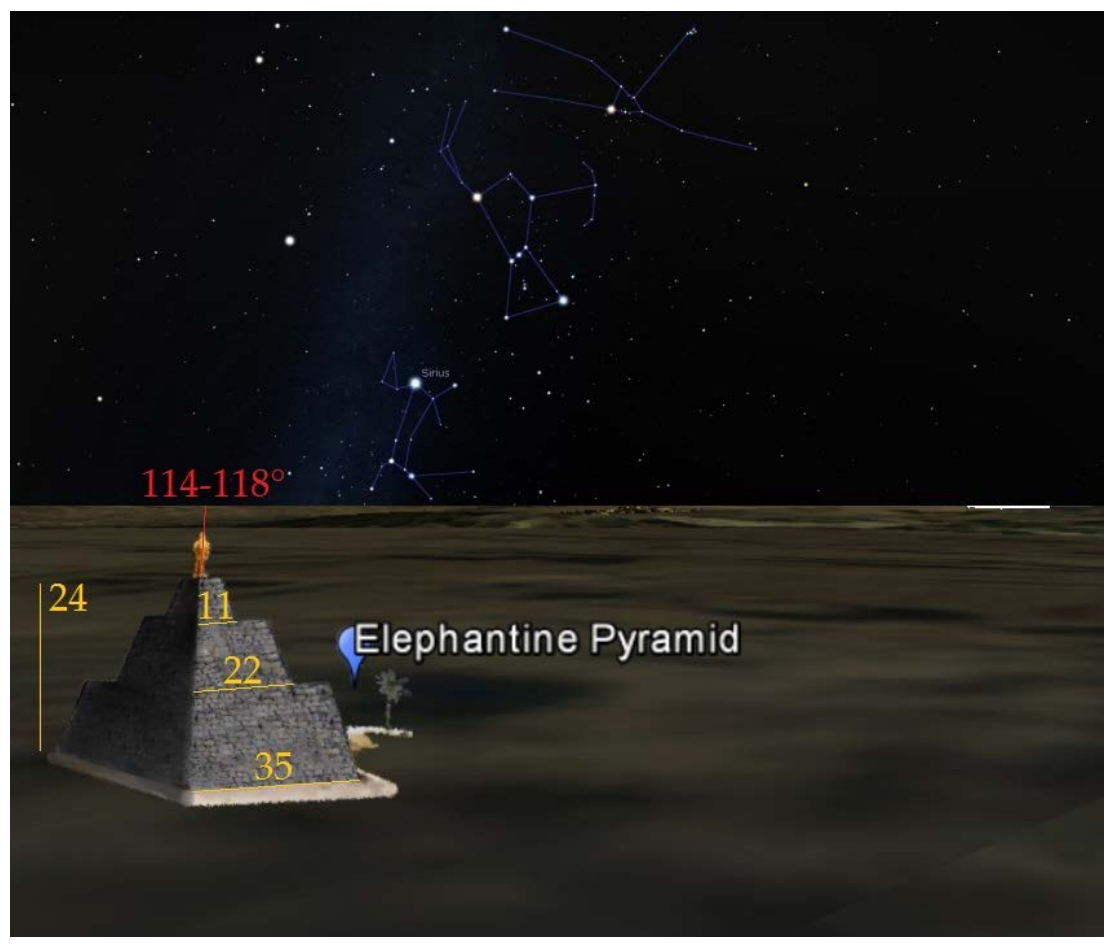

Figure 10. Orientation, heading, and dimensions of Dreyer et al.'s three-step model of the Yebu Pyramid relative to Sirius, Orion, and Taurus in the southeast sector of the night sky. Not drawn to scale. Graphic by M.S. based on Google Earth. 
The duration of this journey as seen from $Y e b u, 58 / 59$ days, is the cubit sum of the first step's base and the estimated height from the pyramid's foundation in Dreyer's model: 35 cubits +24 cubits (Figure 10). The 11-day difference became the 11 cubits base of the pyramid's core on the third step. The height may have encoded an aspect of Elephantine, because it was thought to be higher than Memphis explaining the direction of the Nile's flow from Upper to Lower Egypt.

In this three-step model, the second base is circa 22 cubits long. Geometrically, 22 is the diameter of a circle 69 - 70 cubits round, numerically the true period of Sopdu's visual absence observed from Iunu. 70 days is also $1 / \pi \varphi$ of a sidereal lunar year ( 356 days, Seyfzadeh, 2017; see below), geometrically represented as the short leg of a Kepler Triangle relative to the circumference of its corresponding circle (Figure 8). Knowing $22 / 70$ and $70 / 356$ (i.e. $\pi \sim 70 / 22$ or $356 / 113$ ) meant the Golden Ratio was also within reach expressed as 113/70. Thus, two classic, geometric relationships would have been fortuitously captured by three simple observations: The period of invisibility of the star Sirius at Iunu and Yebu (see Figure 9), and the sidereal period of the Moon (Seyfzadeh, 2017; see below), long before Pythagoras and Euclid (re)discovered them.

70/113 also approximates the seqed (side slope) of three pyramids: Meydum, Khufu, and Menkaure. Many theories have been proposed to explain the idea behind why this pyramid angle was chosen, because it converts a pyramid into a cornered model of a half-sphere and opens a mathematical gateway connecting the worlds of straight and curved dimensions. Those theories based on advanced knowledge of the mathematical constants $\varphi$ and $\pi$ (e.g. insinuated by John Taylor and Flinders Petrie) could find a reasonable explanation in the straight forward numerical astronomy presented here as an alternative to both the more orthodox and more esoteric ones. The main point is that the constants were at hand via the measured periods of Sirius and the Moon.

If the builders recognized this geometry, the significance of the 22-cubit base would have been the ostensibly straight path along the horizon from west to southeast which corresponded to the curved paths taken by Sopdu/Horus either witnessed during its visible period or imagined after its cosmic setting. Wittingly or not, both relationships, radius to circle (11/70) and diameter to circle (22/70), are embedded in the Yebu Pyramid's three step bases, if that is how the pyramid was built. If intended, the numerical link between myth and geometry may have inspired the architectural insight that the curved paths of the gods can be imitated with straight lines over corners in the shapes of true pyramids on the ground, a major paradigm shift.

The same link between the golden Horus myth and the geometry of its celestial movements might be seen in the "basket symbol", (Gardiner V30, $n b$ ) used by the Egyptians as an ideogram for "lord/master" and "gold". The written symbol of $32^{\text {nd }}$ century B.C.E. ruler Iry-Hor (Figure 11) shows a falcon sitting on the base of a half-circle in a manner not unlike that shown in the later serekhs used as early as by next ruler Ka. On sealings, also attributed to Iry-Hor, the 


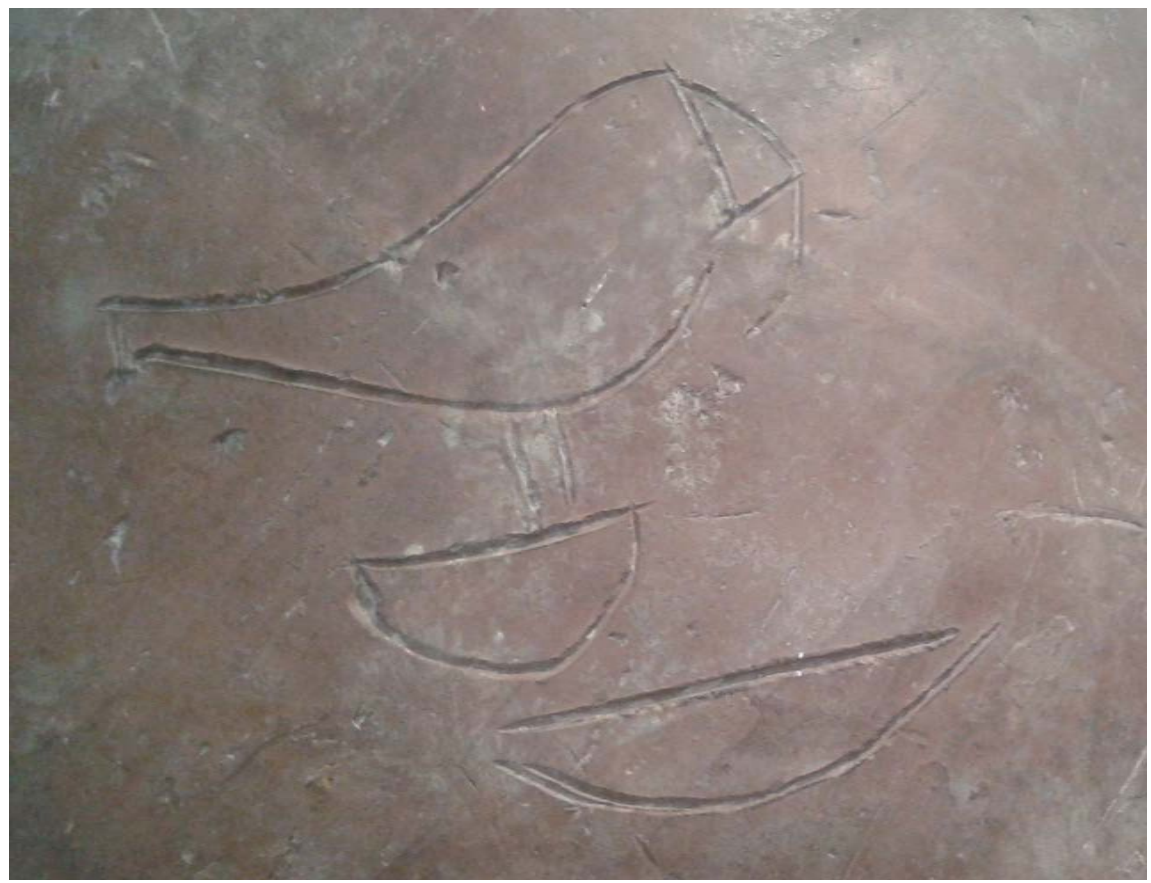

Figure 11. Iry-Hor's title "Lord/Golden Horus" engraved into a vessel from his tomb B1/2 at Abydos, in Upper Egypt. Depicted is a falcon sitting on a half-circle. Ashmolean Museum, Oxford. Attribution: Wiki-User "Iry-Hor", unmodified, CC BY-SA 3.0. Direct link to image: https://en.wikipedia.org/wiki/Iry-Hor\#/media/File:Iry_Hor_name.jpg.

falcon is instead shown holding the mouth symbol " $\mathrm{r}$ " suggesting this written version spelled the name itself. The half-circle probably had another meaning related to kingship. In later spellings of the sound "Iry", the words jryujkhut mean horizon dwellers and jryjui is a title of Horus, "keeper of two gates" (Budge, 1920: 70). Therefore, the Horus symbol of Iry-Hor, its geometric symbolism that is, comports well with an attribute of Sopdu, i.e. the semi-circular shape of both its visible celestial and imagined duat paths relative to the straight horizon, later represented as a palace façade with gate and the labrys symbol. Of course, the Horus symbol may have originated from the sight of a falcon sitting on a weaved basket or from some other inspiration, but the paths of Sopdu is one way to explain it.

Besides at $Y e b u$, there are six other cultic pyramids. They are in Egypt at Seila, Hebenu, Sinki, Nubt, El Kula, and El Ghenimiyain that order from the Faiyum to Yebu. As best as can be reconstructed, the latter five had heights and base lengths like Yebu (Swelim, 2017), but their orientations vary (Belmonte et al., 2005). Only the MSP at Seila is oriented to the cardinal directions, apparently the first pyramid ever. Some others seem to target the circumpolar region as did the Step Pyramid of Djoser (Bauval \& Brophy, 2013) suggesting a common and continuous theme during the Third and early Forth Dynasty. Belmonte et al. (2005) speculate that during the 27th century B.C.E., Ursa Major reached a low enough altitude for it to be no longer visible in Upper Egypt which may have meant it could indeed "perish". For example, Stellarium gives an altitude of $8^{\circ}$ 
for Alkaid's meridional crossing on Julian Day 770908 (J.D. 8/19/2601 B.C.E) at Aswan/Elephantine. By comparison, for Sirius to be visible at an altitude of only $2^{\circ}$ requires it to be circa 50 times brighter than Alkaid. The sudden "perishing" of Alkaid believed to be imperishable may have triggered the search for a new orientation to mark the celestial gate for the dead Kings' souls, for example $\mathrm{Ko}$ chab in Ursa Minor and Thuban/ a Draconis, the two targets of the north-facing shafts from the Queen and King chambers (Bauval \& Gilbert, 1994). Therefore, a plausible motive for the sudden turning of monuments towards due north by King Sneferu in the 26th century B.C.E. was the temporary visual absence of Alkaid in Upper (and Lower?) Egypt each year which had gradually developed due to precession.

Besides a new orientation theme, the MSP designer evidently chose a certain set of dimensions. To prove that the Yebu Pyramid also ushered in a new numerical building code of sacred dimensions, we must look for it in later monuments. Evidence of a subsequent geometric design scheme can be found in the dimensions of Khufu's sarcophagus ${ }^{23}$, Khufu's King Chamber ${ }^{24}$, and Khafre's Pyramid $^{25}$, all of which may be based on the Egyptian (3-4-5) triangle. This design theme may have been that of Hemiunu's uncle and successor Ankhaf who likely served under the late Khufu, Djedefre and Khafre. Like his predecessors Hemiunu and Nefermaat, he was "The Greatest of the House of Thoth".

The building sequence of pyramids between Seila and Khafre extends from the two step-pyramid cores E1 and E2 of the Meydum Pyramid, the Bent Pyramid (Dashur-south), the Red Pyramid (Dashur-north), and the casing of the Meydum Pyramid (E3), all under Sneferu, and then to the Great Pyramid under $K h u f u^{26}$. It is possible that these pyramids were all designed by a father-son team of architect-priests from the "House of Thoth", Nefermaat and Hemiunu. Belmonte et al. speculate that the two Dashur pyramids were built to represent the crowns of Upper and Lower Egypt (Belmonte \& Magli, 2015). According to this idea, the first true pyramid ever built was to be a symbol of Upper Egypt, and so it is in this monument, the Bent Pyramid, where familiar dimensions which related to the country's south should be apparent.

The Bent Pyramid's design started on a base tier 300-cubits wide later lengthened to 360 (Stadelmann, 1997). At a height of 90 cubits the side-slope was narrowed on a platform base of 232 - 234 cubits and the pyramid rose in this second tier for another 110 cubits for a total height of 200. Debate persists as to why these changes were made, but the second tier's core design features two elemental dimensions scaled-up by a factor of four to create the first ever true pyramid in Egypt: The half-period of Sopdu's annual invisibility at Yebu,

\footnotetext{
${ }^{23}$ i.e. 12-16-20 palms diagonally across left and right from the center of the granite box to carve out the interior. Two halves $13 \times 14 \times 15$ palms for the exterior. This is a very close match to Petrie's measured values.

${ }^{24}$ i.e. $15-20-25$ cubits.

${ }^{25}$ i.e. $205 \frac{1}{2}-274-342 \frac{1}{2}$ cubits.

${ }^{26}$ Followed by the pyramids of Djedefre, Baka or Setka, Khafre, and Menkaure.
} 
$29 / 2914^{\circ}$ days and the sidereal monthly period of the Moon, 271/2 days (Seyfzadeh, 2017; Figure 12). The latter is simply the number of days it takes the Moon to return to a certain star or group of stars after one revolution around Earth within the resolution of an observer's eye $e^{27}$. Another significance of the base at $116 / 117$ is the timing of the Sokar festival's date 116 days after wp-rnpt.

At Dashur-north, the 420-cubit base of the Red Pyramid incorporates the half-period of Sopdu's annual invisibility at Iunu, 35 days, scaled-up by a factor of 12 (or by 6 to yield the half-base). This factor itself carries relevance to heliacal risings because they occur in general when a new decan appears in the $12^{\text {th }}$ hour of the night at dawn (Krauss in Hornung et al., 2006: 447). The appearance of this factor "12" in the design of the Red Pyramid is, tentatively, new evidence that decans had already been developed in the Old Kingdom long before

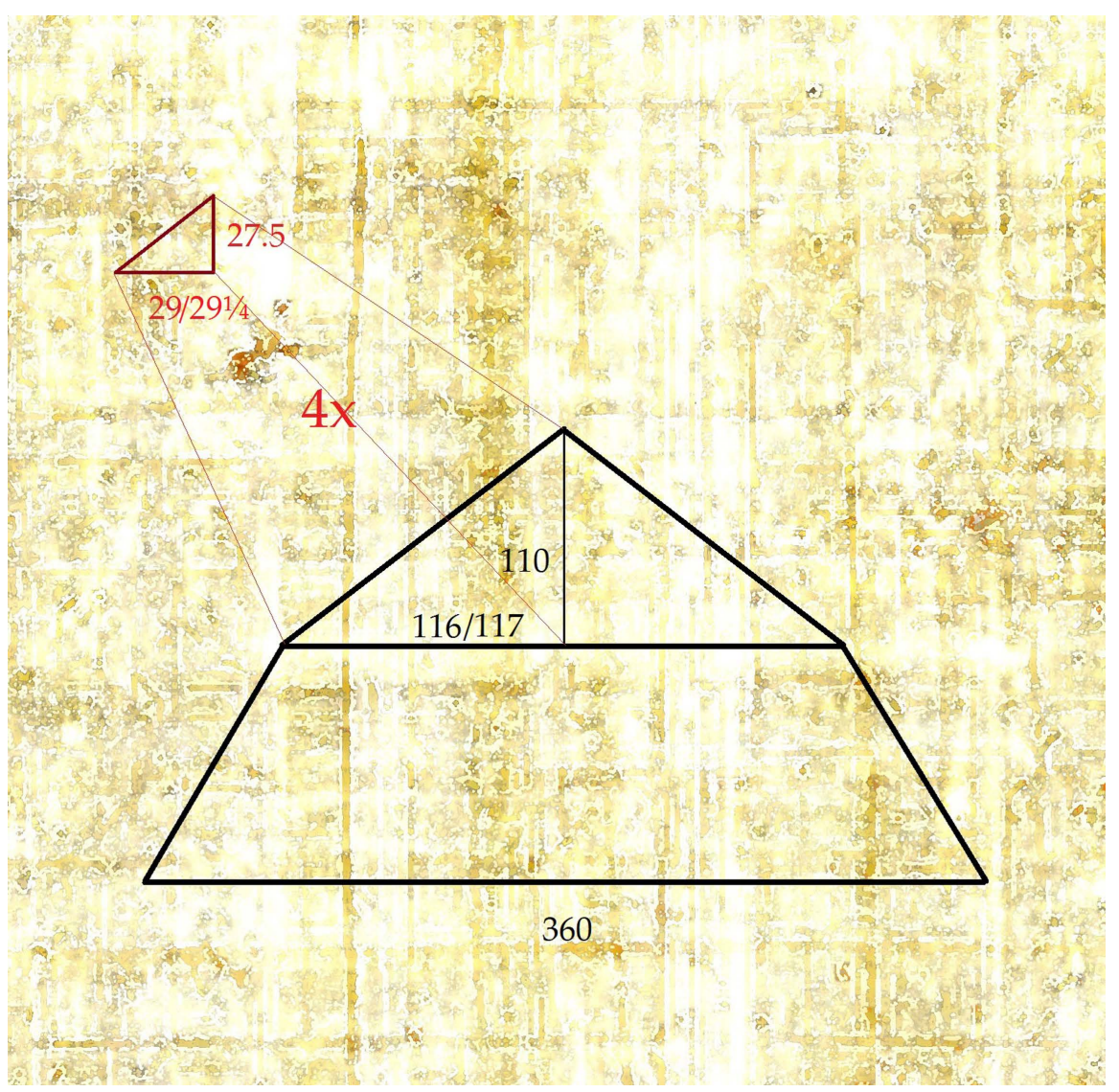

Figure 12. First incorporation of a possible true pyramid design theme based on celestial periods into the top tier of the Bent Pyramid at Dashur-south. $271 / 2$ cubits represented a sidereal lunar month and 29-291/2 days represented the half-period of Sirius' annual invisibility period as observed from the latitude of Elephantine Island. Dimensions and angles based on Stadelmann, 1997: 89. Specifically, the half-base of the second tier is computed using the 7 palms-per- 10 palms seqed $\left(55^{\circ}\right): 360$ cubits $/ 2-90$ cubits $\times 7 \mathrm{p} / 10 \mathrm{p}$. The bottom tier's base was originally built at 300 cubits. Later, 30 cubits were added on each end to produce the final base of 360 cubits. Graphic by M.S.

${ }^{27}$ Annually, the Moon returns to an identical star position after almost 13 revolutions, circa 356 days, the number in cubits of the side-slope of the Great Pyramid (Seyfzadeh, 2017). 
they are known to have been recognized in the Middle Kingdom from coffin lids. Furthermore, the Egyptian name for the Red Pyramid "Kha Sneferu", "Sneferu Shines" in the literal sense of "Sneferu erscheint (German: appears)" (Belmonte \& Magli, 2015) also alludes to wp-rnpt. The word "Kha" spelled with Gardiner N28 is a phonetic word play insinuating the lotus flower (Gardiner M12), a symbol of the Ogdoad. The water lily Nymphaea caerulea rises from under the water surface over days and then opens its calyx in the morning. The metaphor is a perfect description of a heliacal rising. The English "shines", incompletely captures this meaning and neither does "appears". "Kha" captured both in one.

What height was intended for the Red Pyramid is unclear because the side-slope angles of the four sides are not even and the actual height deviates from the probably intended seqed of 71/2 palms per cubit (Stadelmann, 1997) resulting in a probable range of $196-200$ cubits. The best fit is an elemental model length of 33 cubits, scaled-up by a factor of 6 and this design may have represented the invisibility period of Sopdu seen at Iunu in some years with clear visibility, i.e. 68 days $(35+33)$. No obvious lunar theme appears in this design.

At Meydum and Giza, however, like at Dashur-south, a common design theme incorporating the periods of Sirius and the Moon can be distilled from expanded dimensions and even the expansion itself appears non-trivial, but deeply rooted in theology. Even the Yebu Pyramid alone, where no obvious ${ }^{28}$ lunar theme appears, relates and I would like to discuss this latter model theme first for comparison.

Khufu's Great Pyramid (G1) was built on the Giza plateau after the Pyramid of Meydum was cased. Its theoretical height, if fully capped, would have been 280 cubits and its base, fully cased, can be reconstructed at 440 cubits (Petrie \& Hawass, 1990: 11-13). Various authors (e.g. Napoleon's savants, Petrie, Lepre, Pochan, Isler and J. P. Bauval) have observed that the center of the currently exposed core base is slightly indented ${ }^{29}$ visually creating an 8 -sided pyramid in certain lights. Whether this concavity was an intended design feature, its purpose, and whether the outer casing was also indented is unknown.

These features describe the exterior of the Great Pyramid. If one divides the number of days of Sopdu's descent or ascent half-period as seen from Yebu, 29 days, into a civic Egyptian year of 365 days, one obtains 12 4/7, which is a factor any Egyptian architect would have understood (12 cubits 4 palms) and which would symbolize the year in terms of "Yebu duat months", for example. Multiplied by either 35 or 22 cubits this factor yields 440 and 277 cubits, respectively (Figure 13). The former matches G1's base and the latter is 3 cubits shy of the theoretical summit on which a 3 cubit-tall, 4 5/7 cubits-wide pyramidion would have fit closely matching that found by Stadelmann attributed to the Red Pyramid

\footnotetext{
${ }^{28} 291 / 2$ days is the average length of a synodic month and it is known that this period mattered in early dynastic times before the civil calendar (Parker, 1950).

${ }^{29}$ Petrie estimated it to be $1 / 2$ to $1^{\circ}$. For a history of the observation and its interpretation see Larry Orcutt's web-page at http://www.catchpenny.org/concave.html.
} 


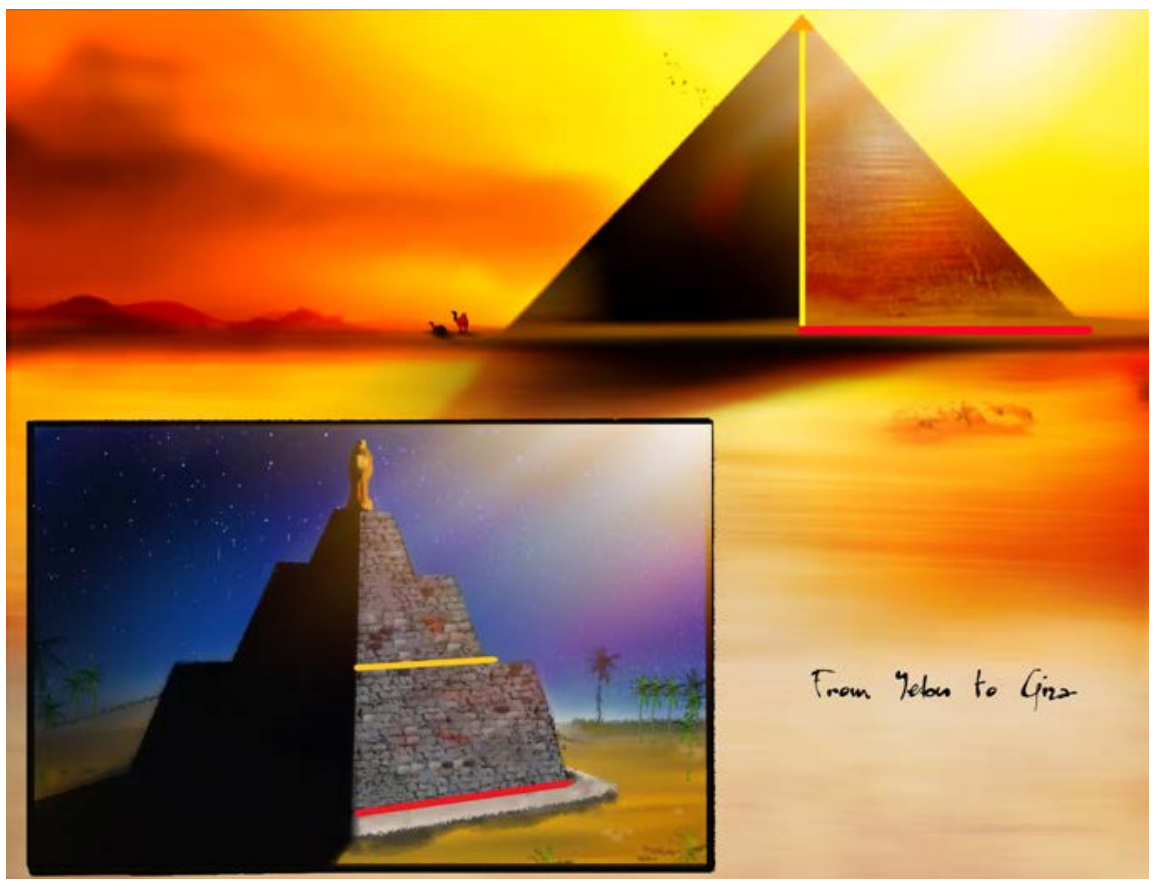

Figure 13. The Yebu Pyramid's ground (35 cubits) and first step (22 cubits) bases in relation to the base (440 cubits) and height (280 cubits) of Khufu's Great Pyramid. The common scale-up factor is $124 / 7$. Note that the yellow line denotes the vertical height of the Great Pyramid, not the slanted slope of its edges (418 cubits). Graphic by Anthony Adomaitis, Asturmas Studios.

(Stadelmann, 1997). In this theme, the base of the Great Pyramid represented Horus' path through the duat and its height was Horus' projected path on the horizon, i.e. a geometric rendition of the semi-circular path the star may have been imagined taking. The meaning of "Khufu's Horizon" now comes into a different light in terms of the timing of the king's resurrection geometrically represented within the dimensions of his pyramid.

This design, originally conceived on $Y e b u$ and scaled-up at Giza, would have numerically enshrined the astronomy of resurrection of the Horus-Kings. It explains the occurrence of the constant $\pi(2 \times 440 / 280)$, Petrie's only admitted speculation as to the idea behind it the Great Pyramid (Petrie\& Hawass 1990: 93) in terms of the geometric relationship between a diameter and its circle and the meaning ancient Egyptians may have attributed to that in terms of the stellar Horus. Since none of the MSP's are fully standing, however, and since only the bases at ground level are still measurable, this putative design theme remains difficult to prove, because it relies on only one of three proposed reconstructions possible (Swelim, 2017; Dreyer \& Kaiser, 1980).

However, there is another, better model which only relies on the solidly confirmed base length of 35 cubits found in all MSPs and deepens the cultural context which may have mattered with respect to scaling-up: The numbers " 5 " and " 8 ". I previously published evidence that the exterior design of the Great Pyramid, its dimensions and angle, can be plausibly explained in astronomic terms as 
a natural calendar which intertwines the invisibility period of Sirius at Iunu and the sidereal orbital period of the Moon $^{30}$ whose measurement was within easy reach of Old Kingdom astronomers (Seyfzadeh, 2017). In the book, I also explain how a model pyramid incorporating these features could have been scaled up to design both the Pyramid of Meydum and the Great Pyramid.

This model pyramid (Figure 14) would have had a base of 55 palms (or cubits whichever), a half-base of $271 / 2$ and a height of 35 . The sidereal lunar period is represented by the half-base in this model and the height represents one half of Sirius' invisibility period as observed from Iunu. These two dimensions alone explain the Kepler Triangle at the core of this pyramid. Any pyramid erected over a Kepler Triangle has a side-slope of $51^{\circ} 50^{\prime}$ and twice its base over its height

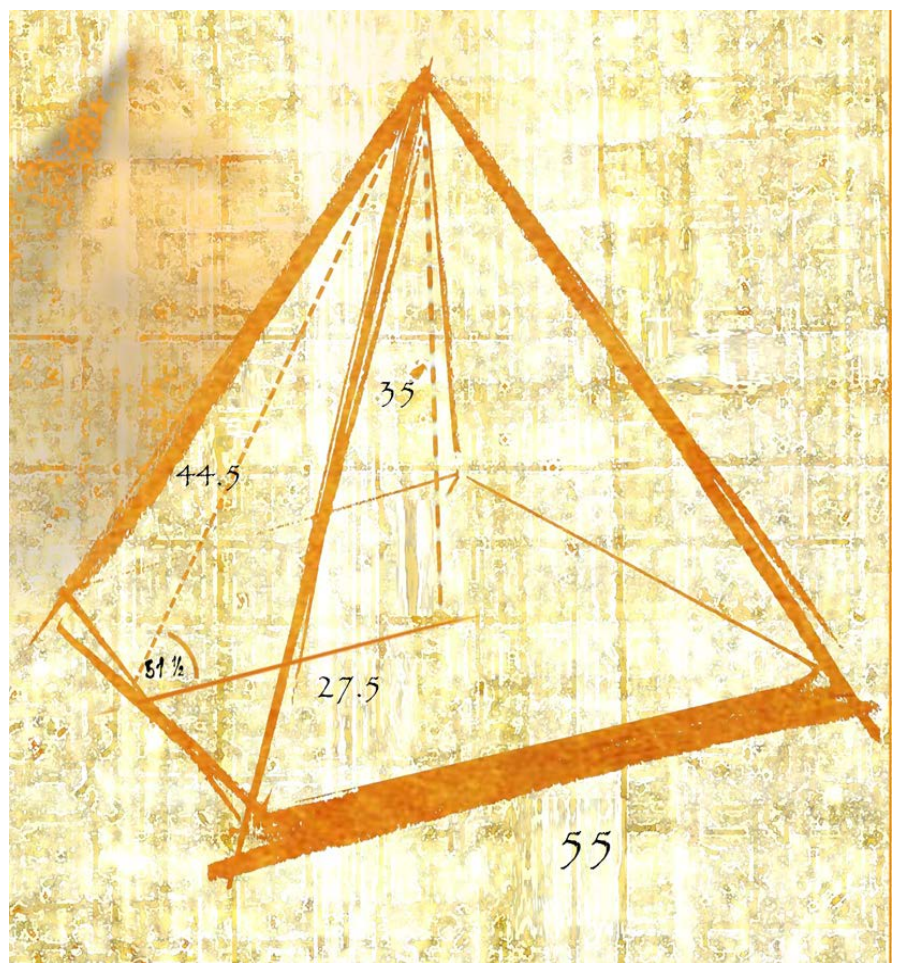

Figure 14. Hypothetical model pyramid from which the Meydum and Great Pyramids' designs could have been derived by scaling-up $5 \times$ or $8 \times$, respectively. The dimensions are based on the invisibility half-period of Sirius (35 days- > cubits) as observable at Iunu in the $26^{\text {th }}$ century B.C.E. and the sidereal period of the Moon (27.5 days- $>$ cubits) when observed relative to a star or constellation near the ecliptic. The relationship between the height and half-base when designed with these lengths incidentally produces a side-slope angle of $51^{\circ} 50^{\prime}$, i.e. a seqed of $5 \frac{1}{2}$ palms run per cubit rise. The core triangle (dashes) which defines this specific design is a Kepler Triangle in which the ratio of the hypotenuse to its short leg approximates the golden ratio (1.618...). Graphic by Anthony Adomaitis, Asturmas Studios.

${ }^{30}$ The modern measurement is 27.3216 days. The natural period commonly believed to be the basis of the Egyptian lunar calendar has always been the synodic month. Yet, Gardiner N11's dual meaning of month/Moon and palm (shsep) in a 7-palm royal cubit suggests a 28 -day month was observed at one time and that this cubit was originally based on it. 
approaches $\pi$. This means neither angle, nor Golden Ratio or $\pi$ need to have been consciously chosen, but their recognition was certainly within reach as I mentioned in the geometry section above. They are incidental to the two input dimension. Therefore, their occurrence in a Kepler Triangle pyramid may not be premeditated, but is also not by random chance, i.e. not coincidental.

The Meydum pyramid was begun as a step-pyramid and later completed as a smooth, cased pyramid (Lehner, 1997) immediately before the Great Pyramid was built. It was 275 cubits wide at the base and 175 high. Embedded in these dimensions we recognize now familiar numbers from Elephantine Island and from the sidereal lunar month. 175 cubits is 35 palms times 35 , or 35 cubits times 5 . The word for the number 5 "thu" or "dayu(t)" linguistically relates to the name of the underworld, the "duat". Five was the number of priests in the House of Thoth, whose grandest member at the time were Nefermaat and Hemiunu, the presumed architect of the Great Pyramid, under Khufu. Five was the number of epagomenal days at the end of the civil year and it was the fifth hour of the night when the spirit of the king resurrected in the duat. Evidently, the number " 5 " was of cultic importance.

This factor also numerically scales up two sidereal lunar periods of 55 days to a length of 275 cubits, the Meydum Pyramid's base and one period of $27^{1 / 2}$ to the half-base of $1371 / 2$ in the core triangle (Figure 15). The relationship between these two periods, Sirius' invisibility (35/70) and the Moon's (271/2/55), yields the special angle of $51^{\circ} 50^{\prime}$, also defining the core triangle at the heart of the Great Pyramid (Figure 16). This triangle became famously known later as a Kepler

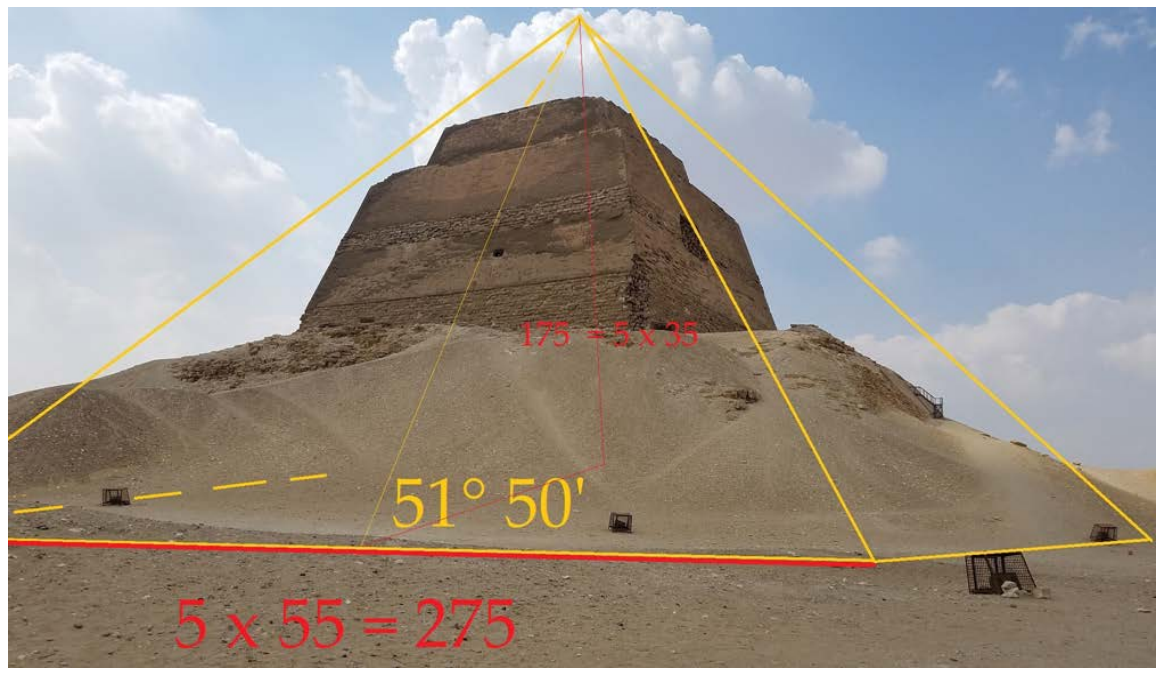

Figure 15. The remains of the Meydum Pyramid built by Sneferu at the outset of the Fourth Dynasty. Originally conceived as an 8 step-pyramid in two phases E1 and E2, it was cased at the end of Sneferu's reign after the Bent and Red Pyramids were completed. The dimensions shown are those of the fully cased pyramid reconstructed from the remaining casing stones in situ. This design is a $5 \times$ scaled-up version of the model pyramid shown in Figure 14. The side-slope angle shown is identical to that of the Great Pyramid and is incidental to the height (175 cubits) and half-base (137.5 cubits) of the pyramid. Photography and design by M.S. 


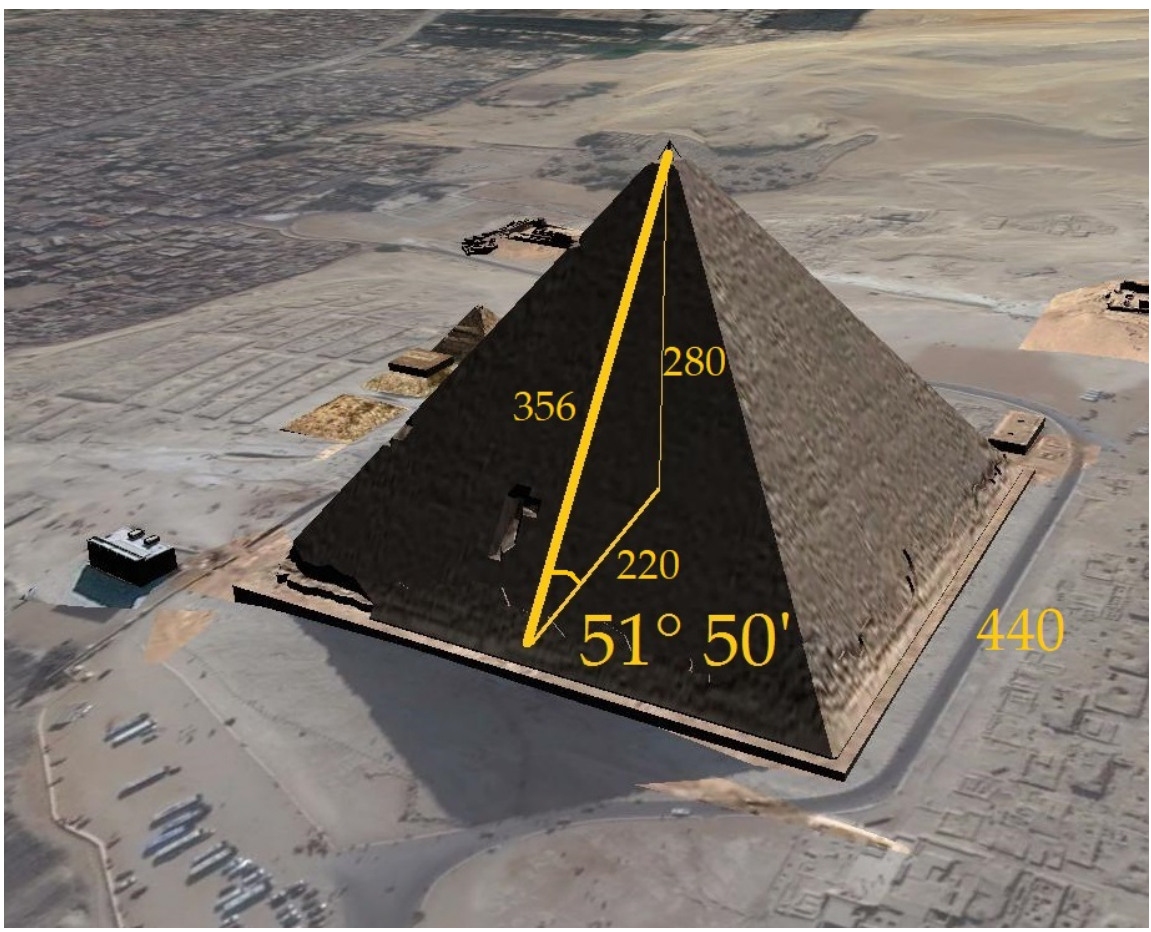

Figure 16. Khufu's Great Pyramid as seen from the northwest. The pyramid's core design is based on a Kepler Triangle whose hypotenuse (356 cubits) is in the golden ratio $(1.618 \ldots)$ to its short leg (220 cubits) incidentally producing a side-slope angle of $51^{\circ} 50^{\prime}$. This design is an $8 \times$ scaled-up version of the model pyramid in Figure 14: $8 \times 35=280$ and $8 \times 27.5=220$. Graphic by M.S. based on Google Earth.

Triangle, defined as a right triangle with edges proportional to $1: \sqrt{ } \varphi: \varphi$ and whose major angle at the short leg is $51^{\circ} 50^{\prime}\left(51.83^{\circ}\right.$, a seqed of $5 \frac{1}{2}$ palms per cubit). It can be concluded that the exterior of the Meydum pyramid, when finally fully cased for no apparent reason, was a scaled-down version of the Great Pyramid by a factor of 5 to 8 . In fact, this enigmatic effort now makes sense.

I think relating these two periods is a plausible and context-appropriate way to explain the occurrence of the Kepler Triangle (Taylor, 1859; Seyfzadeh, 2017) in the design core of both pyramids. Other plausible explanations have been offered: 1) There was only a limited number of seqeds to choose from (Greenberg, 2000) and 2) $5 \frac{1}{2}$ palms per cubit may have been the practical limit in terms of height in a race to build the tallest pyramid. A clever explanation was also proposed by Christopher Bartlett (2014) who proposed that the angle was based on human anatomy. The astronomical "angle" however provides a deeper religious context in my opinion and the same argument applies against the other two theories. Religious context motivating intent should not be ruled out as implausible due to the modern age tacit bias that practical considerations better explain ancient rationales.

Since the common design-theme I propose is preserved in two consecutively built pyramids of different, absolute dimensions, we can speculate that Hemiunu used a scaled-down model (Figure 14). It is even possible that Hemiunu himself 
designed the exterior of the Meydum Pyramid at the end of his grandfather's reign and after his father Nefermaat had $\operatorname{died}^{31}$. The next pyramid after would become that of Khufu and so this theme may have been the very personal signature concept of the one person in charge of both. In the case of the Great Pyramid, Hemiunu would have scaled this model up by a factor of 8 resulting in the observed 5 to 8 relationship between the exterior dimensions of these two pyramids and embedding the same special angle of $51^{\circ} 50^{\prime}$ (Figure 16). The model, either built or more likely drawn on papyrus (Figure 14), would have contained the actual and absolute numbers (35, 55, and 271/2) in cubits. They symbolized the sacred astronomic numbers based on direct time measurements of Sirius and the Moon. A sidereal lunar year, 355 - 356 days, may be represented in the original length of the side-slope of the Great Pyramid, 356 cubits, which also incidentally arises by necessity of the embedded scaled-up dimensions of the half-base and height and the side-slope angle $\left(51^{\circ} 50^{\prime}\right)$ so created.

The Great Pyramid displays eight (8) faces in certain lighting. If this effect was indeed intentionally created and then hidden behind the Tura casing, it further confirms that a theme involving the number " 8 " was at play in the design of the Great Pyramid. This theme extends from the eight-fold scaling-up of the model pyramid, to the eight-year astronomic super-cycle after which a heliacal rising of Sirius concurs with the Moon in a certain position on the star map (Seyfzadeh, 2017), to the eight faces created by the small indent on center of the triangular faces. What was, if any, a significant religious theme relating to the number "8"?

This, too, takes us to Thoth, the Egyptian Ibis god associated with the sciences, with writing, and with the Moon. Thoth was worshiped at the 15th nome ("Wenet”) of Upper Egypt in a city now called El-Ashmunein, Egypt (Hermopolis magna), then "Khemenu" (City of the Eight). It was the spiritual center where the cosmogony of the Ogdoad ("The Eight") originated, the belief that the world was created from the primordial chaos of the four concepts of water, darkness, invisibility, and eternity symbolized by 4 divine couples of eight gods, male frogs and female snakes, who brought into existence from cosmic chaos a lotus flower (the blue Egyptian water lily Nymphaea caerulea) from whose calyx the Sun emerged in the moment of creation. The Egyptian Lotus typically produces a calyx made up of rows of eight petals. It slowly rises to the water surface over days' time and then opens its calyx for a few hours after sunrise. This shining manifestation of $R e$ from the Lotus was called "kha". The concept of a group of eight gods pervades Egyptian history and several renditions are documented (Wilkinson, 2003: 77-78). On the Stele of Wepemnefret in the top register, a hint of the Ogdoad can be appreciated in the symbol of the frog symbolizing one of the titles held by this son of Khufu and a direct reference to the Ogdoad occurs on the west gable in Unas tomb (Recitation 4, Allen, 2005: 17).

The most striking evidence to show how the Ogdoad might have played into

\footnotetext{
${ }^{31}$ Explaining why Nefermaat was buried at Meydum and not at Giza.
} 
the design of the Great Pyramid is the small indent on its four faces (reviewed by Schoch \& McNally, 2005: 219-220). The indent has been calculated to be 0.9215 $\mathrm{m}$ from the four side centers of the presumed perimeter of the casing stones vertically inward to the core masonry immediately behind (Bauval, 2016) it. It has been roughly measured on-site to be about three feet (Alan Green, personal communication) and more accurately at $0.92 \mathrm{~m}$ by Pochan (1971). These values agree with Petrie's lower estimate of the angle the indent produces at the pyramid corners where the outer core limit and the casing perimeter would have met, i.e. $\sim 1 / 2^{\circ}$.

Remarkably, the identical length, 0.9215 meters, can be obtained by taking 8 ("Khemenu") $\times$ 1/1000 ("Re-Kha"; Egyptian unit fractions were expressed with the mouth symbol Re over some denominator; kha also means "thousand") of the half-base, 220 cubits $^{32}$ which suggests that this could have been another intended design feature in the overall Ogdoad-inspired theme. Were the masters of the House of Thoth, Nefermaat, Hemiunu, and Ankhaf, as was Imhotep a century earlier (Bauval \& Brophy, 2013), on a (secret?) mission to speak in numbers instead of words? Did they use architecture to numerically preserve the memory of an ancient order from becoming forgotten and obsolete?

Nefermaat left this epitaph in his tomb: "He is one who made his gods ${ }^{33}$ in writing that cannot be erased" presumably referring to the special inscription technique used. The only other inscription where this technique was to be used again is on a statue presently kept at the Roemer-und Pelizaeus-Museum in Hildesheim, Germany: The statue of his son Hemiunu.

Could this be a veiled reference to the Hermopolitean cosmogony of the House of the Moon god Thoth, written into the monumental dimensions of the pyramids? The answer may lie hidden within the Meydum Pyramid, steps away from Nefermaat's mastaba. Starting with innermost layer 1 of its E1/E2 core of concentric squares, the accretive base lengths of the 8 layers beneath the casing E3 were likely meant to be $100,115,130,150,169,188,207$, and 226 cubits, respectively (Petrie, 1892: 7; 1 cubit $=\pi / 6 \mathrm{~m} ; 1$ inch $=2.54 \mathrm{~cm}$ ). Outer layers 5-8 each increase in 19-cubit increments, making the pyramid 38 cubits wider per each two outer layers.

In keeping with the idea of four divine couples in the Ogdoad, these eight layers can be viewed as 4 pairs of two summed adjacent bases. The sum of inner layers 3 and 4 is 280 cubits, $8 \times 35$, the now familiar Sothic half-period of invisibility in Lower Egypt and the original height of the Great Pyramid. The sum of outer layers 5 and 6 is 357 cubits, $13 \times \sim 271 / 2$, the number of then observable sidereal periods of the Moon completed per civil year of 365 days. As a reminder to the reader, both periods were later incorporated into the dimensions of $\mathrm{E} 3$ by scaling them up 5-fold and into the Great Pyramid through an 8-fold expansion.

The sum of inner- and outermost layer couples $1+2$, and $7+8$ is 648 cubits,

${ }^{32} 220$ cubits $\times 8 / 1000 \times \pi / 6=0.9215338 \mathrm{~m}$. The indent is exactly $1 / 1000$ of the perimeter, 1.76 cubits.

${ }^{33}$ Officially interpreted to mean "signs" but "gods" (i.e. "neteru") is in fact the literal translation. 
which when multiplied by $13 / 8$ is 1053 . Starting the count on a conjunction at New Moon, this is the period in days of 38 true sidereal lunar periods $(27.322$ days), 1038 days, plus 15, i.e. the first Full Moon after New Moon returns to a certain star position on the ecliptic and 42 days short of three civil years (1095 days). This was a key insight which periodically related the sidereal lunar month with the synodic month suggesting that if Nefermaat designed the core of the Meydum Pyramid, he then also knew the true sidereal period of the Moon, 27 9/28 days, from long-term observations relative to the one-period observation of $271 / 2$ and had related it to the long-known synodic month in this way, i.e. $38 \times 27$ $9 / 28+7=38 \times 271 / 2 ; 1038+15=1053$.

This peculiar association between the numbers 19/38 and the Ogdoad has a conspicuous precedence at Saqqara in Imhotep's design of the hypostyle colonnade which leads into Djoser's Step-Pyramid complex. Its entry is lined with 12 +8 pairs of opposing pillars, 36 of which with 17 flutes and 4 at the end on the south side with 19. The colonnade exits to a portico made of four pairs of columns each with 19 flutes (John Anthony West, 2015; Alan Green, personal communication). The number of flutes in each of the three segments are 408; $136,76 / 68$; 152, respectively (Alan Green, personal communication), which conspicuously fit the equation $408 / 3 \times 76 / 68=136 \times 19 / 17=152$. The numbers encode a mathematical operator, $136 / 408 \times 76 / 68=19 / 51$, with great astronomic relevance: It show-cases how both the Sothic year (3651/4 days) and the civil Egyptian calendar (365 days) relate to two lunar super-cycles based on the synodic or the sidereal lunar month.

To wit, the colonnade alludes to the Metonic cycle (West, 2015), a 19-year period after which the synodic lunar month comes into synchrony with the tropical year, virtually identical to the Sothic year during the Old Kingdom. This period of 6940 days is approximated by 17 times the number of flutes in the first 12 pairs of pillars, $408 \times 17=6936$ days. The same factor 17 scales up the number of flutes in the portico, $8 \times 19=152$, to 94 sidereal lunar months of $\sim 271 / 2$ days, i.e. 2584 days. The middle segment of 8 pairs of pillars encodes the conversion factor between these two lunar periods, $19 / 51$, i.e. $136 / 408 \times 76 / 68$. Finally, the civil year of 365 days relates to these two lunar cycles by 136 , i.e. $19 / 51 \times 365$, the number of flutes in the first half of segment 2. The overarching theme, it appears, was an attempt to make sense of several astronomic cycles and how they related to each other.

The numbers used by Imhotep and Nefermaat at Saqqara and Meydum therefore suggest that several super-cycles of the Sun and the Moon were also then known in addition to the Sothic cycle previously noted by Bauval and Brophy (2013). If Nefermaat, like Imhotep before him, indeed intended this playful display of numerical astronomy, his epitaph, in more ways than one, rang true then as it does now: The essence of the gods of the Ogdoad and Thoth he numerically created inside the Meydum Pyramid remained un-erased for Petrie to measure them. As shown earlier, Hemiunu apparently employed an equally 
clever scheme to hide the numerical spirit of the Ogdoad as eight half-faces in the Great Pyramid's core masonry by slightly indenting the bases at the center by an unmistakable fraction.

One other pyramid, possibly designed by Ankhaf after Khufu and before Khafre came to power, deserves mention: The Pyramid of Djedefre, Khufu's son. Djedefre honored his father post-mortem with a pit for Khufu's boat south of the Great Pyramid, presumably, to help him pass through the underworld at night and resurrect with Re. A distinctive feature of Djedefre's pyramid (and of Lepsius XIII, possibly belonging to Djedefre's son Baka) is a steep ramp leading into a T-shaped subterranean pit cut deep into the bedrock where the sarcophagus chamber was to be placed $r$ essentially recreating the underworld. Above this basement, the pyramid was $106.2 \mathrm{~m}$ wide (203 cubits; half-base 101.5 cubits) and $57-67 \mathrm{~m}$ tall $\left(109-128\right.$ cubits) with a probable seqed of $6 \frac{1}{4}\left(48^{\circ}\right)-5 \frac{1}{2}\left(52^{\circ}\right)$ palms-run per cubit-rise (Lehner, 1997: 120). Due to extensive destruction, the pyramid's height and angle can only be narrowed down to a close range, but one good fit for these values is a 3.5x expansion of a model pyramid with a half-base of 29 cubits (half-period in days to wp-rnpt at Yebu) and a height of 35 cubits (half-period in days to wp-rnpt at Iunu) producing a seqed of 53/4 palms per cubit $\left(50.36^{\circ}\right)$ based on the same celestial theme proposed here to have inspired the design of the Pyramid on Elephantine Island. The significance of 3.5 is that $35 \times$ "1/10" (pronounced "Re-Medju") might be a phonetic play on "Re-Medjut", i.e. "Sun-Cave".

\section{Conclusion}

In summary, I have presented evidence that the dimensions of the minor step pyramid on Elephantine Island mattered besides its orientation to rising Sirius. When keeping track of time and Nile began to fail due to calendar drift and precession, Third Dynasty astronomers may have turned their focus on the yearly invisibility period of the stellar Horus and recorded the days as cubits in the step design. From this crucial transition at Yebu, the Pyramid Age advanced from step-pyramids to true pyramids which gave their architects an added medium to express a numerical message. Once the stellar cycle of the Moon was observed and measured, an elemental model pyramid of two intertwining sidereal cycles was devised, one represented in the model's height and one in its base.

Thus, the outer dimensions of smoothly cased pyramids encoded a new concept of orderly time and four true pyramids expressed it. Further imbued into their architecture were the cultic numbers of Khemenu, five and eight, used to scale-up the elemental model into the designs of the Pyramid at Meydum and the Great Pyramid, respectively. This was to become the unmistakable imprint of a cosmogony whose days were numbered when attention shifted (back) to that of Iunu.

While the astronomic relationship between the period of Sirius' invisibility and the lunar orbit, when viewed within the theological context of the Ogdoad's 
teaching, may not explain all peculiar features of the Great Pyramid, it can help demystify those related to its exterior design. This includes at least some of the geometric allusions to geodetic quantities noted by Great Pyramid researchers who tacitly assume that perimeter and angle were premeditated design choices to make these allusions, a notion typically dismissed by traditional Egyptologists, who believe they are coincidental.

An alternative explanation to both notions and a possible bridge between them is offered in this paper; to wit, the perimeter is incidental to a scaled-up premeditated elemental base of $271 / 2$ cubits and the angle is incidental to the base's relationship with the pyramid's scaled-up height of 35 cubits, both of which stem from astronomical periods nevertheless. In other words, the perimeter and side-slope angle of the Great Pyramid exist by necessity of these other choices. They were neither randomly nor intentionally chosen and the astronomic connections so made, if unwittingly, were real by virtue of how planetary motion became an incidental measure of planetary geometry relative to that of the Moon.

The findings presented in this paper offer a plausible explanation for a pyramid code, if ancient architects indeed devised it. They squarely place these otherwise bewildering monuments into an Old Kingdom cultural context and show-case the genius of ancient Egyptians who evidently observed the sky, interpreted what they saw within their religious view of the world, and quantitatively embedded these insights and inspirations as sacred, maybe secret, monumental messages.

\section{Dedication}

To the People of Egypt.

\section{References}

Allen, J. P. (2005). The Ancient Egyptian Pyramid Texts. Atlanta, GA: Society of Biblical Literature.

Bartlett, C. (2014) The Design of the Great Pyramid of Khufu. Nexus Network Journal-Architecture and Mathematics, 16, 299-311. https://doi.org/10.1007/s00004-014-0193-9

Bauval, J.-P. (2016). The Concavity of the Great Pyramid: A Design Feature? Did the Designer Know the Meter Unit? https://www.academia.edu/27553148/THE_CONCAVITY_OF_THE_GREAT_PYRA MID_a_design_feature_Did_the_designer_know_the_Meter_Unit

Bauval, R., \& Brophy, T. (2013). Imhotep the African, Architect of the Cosmos. New York City: Disinformation Books.

Bauval, R., \& Gilbert, A. (1994). The Orion Mystery: Unlocking the Secrets of the Pyramids. New York: Three Rivers Press.

Belmonte, J. A., Shaltout, M., \& Fekri, M. (2005). Astronomy and Landscape in Ancient Egypt: Challenging the Enigma of the Minor Step Pyramids. Papers on Ancient Egypt (TdE), 4, 7-18. 
Belmonte, J. A., \& Magli, G. (2015). Astronomy, Architecture and Symbolism: The Global Project of Sneferu at Dahshur. Journal for the History of Astronomy, 46, 173-205. https://doi.org/10.1177/0021828615582356

Breasted, J. H. (1912).Development of Religion and Thought in Ancient Egypt. New York: Charles Scribner's Sons.

Budge, E. A. W. (1920). An Egyptian Hieroglyphic Dictionary in Two Volumes. London: John Murray.

Burton, A. (1972). Diodorus Siculus. Book I, A Commentary. Leiden: E.J. Brill.

Dreyer, G., \& Kaiser, W. (1980). Zu den kleinenStufenpyramiden Ober-und Mittelägyptens. Mitteilungen des Deutschen Archäologischen Instituts, Abteilung Kairo (MDAIK), No. 36, von Zabern, Mainz 1980, 43f.

El-Sabban, S. (2000). Temple Festival Calendars of Ancient Egypt. Liverpool: Liverpool University Press.

Fairman, H. W. (1935). The Myth of Horus at Edfu: I. The Journal of Egyptian Archaeology, 21, 26-36. https://doi.org/10.2307/3854487

Gaballa, G. A., \& Kitchen, K. A. (1969). The Festival of Sokar. Orientalia NOVA SERIES, $38,1-76$.

Gantenbrink, R. (1999). Ascertaining and Evaluating Relevant Structural Points Using the Cheops Pyramid as an Example. http://www.cheops.org/

Gautschy, R. (2012). http://www.gautschy.ch/ rita/archast/sirius/siriuseng.htm

Greenberg, R. (2000). The Slopes of the Egyptian Pyramids. https://www.math.washington.edu/ greenber/pyressay.html

Hassan, S. (1960). The Great Pyramid of Khufu and its Mortuary Chapel. Excavations at Giza, Season 1938-39, Vol. X.

Hawass, Z. (1996). The Discovery of the Satellite Pyramid of Khufu (GI-d). In P. Der Manuelian (Ed.), Studies in Honor of William Kelly Simpson (pp. 379-98). Boston: Museum of Fine Arts.

Hornung, E., Krauss, R., \& Warburtin, D., A. (2006). Ancient Egyptian Chronology. Handbook of Oriental Studies, Section One: The Near and Middle East. Boston: Brill, Leiden, Vol. 83: 116-123.

Ingham, M. F. (1969). The Length of the Sothic Cycle. The Journal of Egyptian Archaeology, 55, 36-40. https://doi.org/10.2307/3855998

Lehner, M. (1997). The Complete Pyramids. Solving the Ancient Mysteries. London: Thames \& Hudson Ltd.

Parker, R. (1950). The Calendars of Ancient Egypt, Studies in Ancient Oriental Civilization. Chicago: The University of Chicago Press, No 26.

Petrie, W. M. F (1892). Medum. London: David Nutt.

Petrie, W. M. F., \& Hawass, Z. (1990, Orig: 1883). The Pyramids and Temples of Gizeh. London: Histories \& Mysteries of Man.

Pochan, A. (1971). L'Enigme' de la Grande Pyramide. Paris: Robert Laffont.

Schaefer, B. E. (2000) The Heliacal Rise of Sirius and Ancient Egyptian Chronology. Journal for the History of Astronomy, 31, 149-155. https://doi.org/10.1177/002182860003100204

Schoch, R. M. \& Bauval, R. (2017). Origins of the Sphinx: Celestial Guardian of Pre-Pharaonic Civilization. Rochester, NY: Inner Traditions.

Schoch, R. M., \& McNally, R. A. (2005). Pyramid Quest: Secrets of the Great Pyramid and 
the Dawn of Civilization. New York: Penguin Group.

Seyfzadeh, M. (2017). The Khnum-Re-Horakhty Cycle: The Idea behind the Architectural Design of Khufu's Great Pyramid (2nd ed.). Lake Forest: CreateSpace Independent Publishing Platform.

Shonkwiler, R. (2014). The Behdetite: A Study of Horus the Behdetite from the Old Kingdom to the Conquest of Alexander. Doctor's Thesis, Chicago, Illinois.

Smith, G. E., \& Dawson, W. R. (2009). Egyptian Mummies. New York: Routledge.

Stadelmann, R. (1997). Die Aegyptischen Pyramiden. Vom Ziegelbauzum Weltwunder. Mainz: Verlag Philipp von Zabern.

Swelim, N. http://nabilswelim.com/minor.asp

Taylor, J. (1859). The Great Pyramid; Why Was It Built \& Who Built It? London: Longman, Green, Longman, and Roberts.

Verner, M. (2010). Several Considerations Concerning the Old Kingdom Royal Palace. Anthropology, XLVIII, 91-96.

Wells, R. A. (1985). Sothis and the Satet Temple on Elephantine: A Direct Connection. Studien zur Altägyptischen Kultur (pp. 255-302). Hamburg: Helmut Buske Verlag $\mathrm{Gmb} \mathrm{H}$.

West, J. A. (2015). https://youtu.be/CxcdGB3HvMw

Wilkinson, R. H. (2000). The Complete Temples of Ancient Egypt. New York: Thames \& Hudson.

Wilkinson, R. H. (2003). The Complete Gods and Goddesses of Ancient Egypt. New York: Thames \& Hudson. 